\title{
Donor Substrate Specificity of Bovine Kidney \\ Gamma-Glutamyltransferase
}

\author{
by \\ Anita A. Agblor \\ A Thesis \\ presented to \\ The University of Guelph
}
In partial fulfilment of requirements
for the degree of
Master of Science
in
Molecular and Cellular Biology

\author{
Guelph, Ontario, Canada
}

(C) Anita A. Agblor, November, 2012 


\section{ABSTRACT \\ DONOR SUBSTRATE SPECIFICITY OF BOVINE KIDNEY \\ GAMMA-GLUTAMYLTRANSFERASE}

\author{
Anita Agblor \\ University of Guelph
}

Advisor:

Dr. P. David Josephy

Mammalian $\gamma$-glutamyltransferase (GGT) is a glycoprotein consisting of two subunits - a light chain and a heavy chain. The light chain contains the catalytic activity; the heavy chain anchors the protein to the membrane. GGT catalyzes the hydrolysis of the $\gamma$-glutamyl isopeptide bond of glutathione conjugates, releasing glutamic acid, or the transfer of the $\gamma$-glutamyl group to an acceptor substrate. The specificity of the enzyme for xenobiotic donor substrates has not been fully characterized. The transpeptidation activity of bovine kidney GGT was measured with glycylglycine as acceptor substrate and several glutathione conjugate donor substrates, representative of detoxication products of polycyclic aromatic xenobiotics. HPLC separation with UV detection was used for quantitation. The commonly-used chromogenic donor substrate $\gamma$-glutamyl-p-nitroanilide was also tested. Michaelis constants $\left(K_{m}\right)$ were obtained for $\gamma$ glutamyl-p-nitroanilide $(0.74 \mathrm{mM})$, 4-nitrobenzyl glutathione $(0.075 \mathrm{mM})$, 2,4-dinitrophenyl glutathione $(0.30 \mathrm{mM})$, 4-methylbiphenylyl glutathione $(0.12 \mathrm{mM}), 1$-menaphthyl glutathione $(0.23 \mathrm{mM})$, and 9-methylanthracenyl glutathione $(0.22 \mathrm{mM})$, indicating that enzyme activity is affected, but not strongly, by the nature of the S-substituent attached to glutathione, and there is a slight trend of higher $K_{m}$ values with bulkier aromatic S-substituents. 


\section{ACKNOWLEDGEMENTS}

I am very thankful for my advisor, Dr. David Josephy. He has displayed continuous support, patience and guidance throughout my graduate studies. I am grateful that I had the opportunity to work in his laboratory, and to contribute new knowledge to the field of biochemical toxicology.

I am grateful for my committee members, Drs. Richard Manderville and John Dawson, for their constant support and advice. I would also like to thank Drs. George Harauz and Janet Wood for being a part of my examination committee.

I would like to acknowledge all past and present Josephy lab members: Amanda Pan, Erin Veldman, Michael Ianni, James Poon, Nikole Freeman, Nadine Frost and Minah Hwang, for their technical assistance and friendship.

I am very thankful for my previous employers in Saskatoon: Drs. Satya Panigrahi, Raju Datla, Gordon Gray, and Jeremy Lee. These individuals presented me with an opportunity to gain experience and to acquire new skills in a scientific environment.

I am very grateful for all the professors from the Biochemistry Department at University of Saskatchewan for their constant support, guidance, and advice throughout my undergraduate studies.

I would like to recognize all of my colleagues within the MCB Department: Danielle Visschedyk, Jacqueline Pierce, Marissa Dahari, Ashley Hillier, Ana Loncar, Gavin King, Megan Ross, Danoo Vitsupakorn, Daniel Krska and Iris Selander. These friends displayed endless support throughout my graduate studies. 
I would like to express deep gratitude to my family and friends in Saskatoon and Guelph for their continuous support and advice. I am very grateful for my parents, and their unfaltering demonstration of how goals are attainable through determination and perseverance. 


\section{TABLE OF CONTENTS}

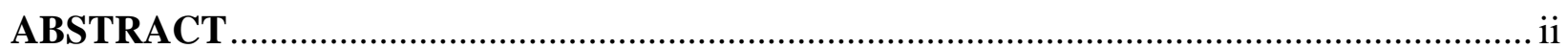

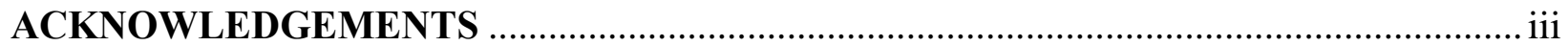

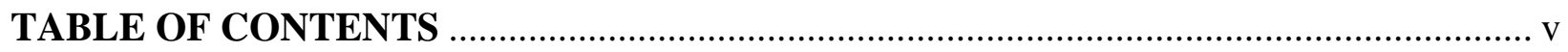

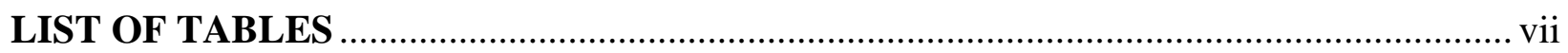

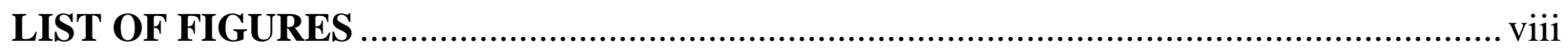

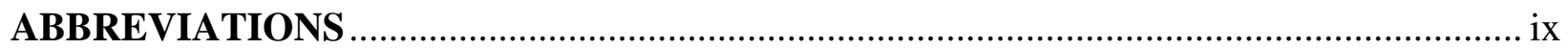

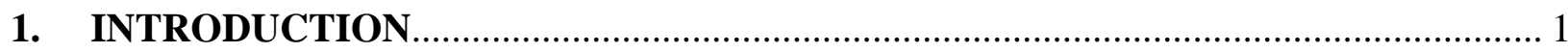

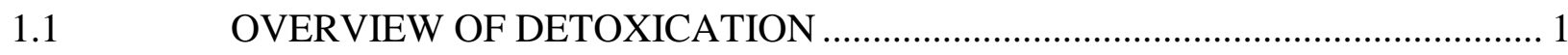

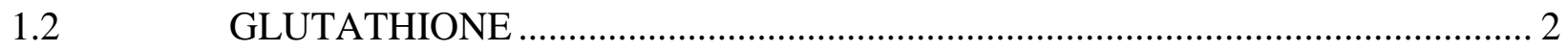

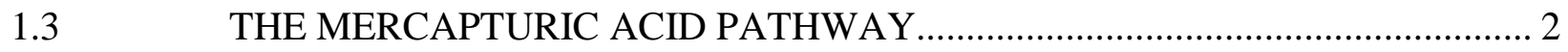

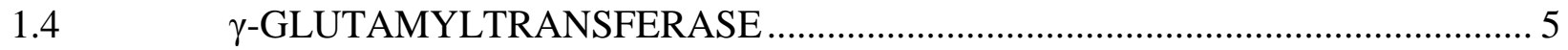

1.4.1 DONOR AND ACCEPTOR SUBSTRATES ...................................................... 6

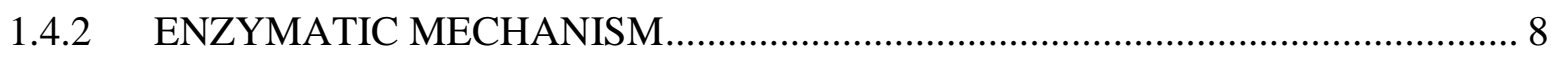

1.4.3 OTHER ENZYMES WITH $\gamma$-GLUTAMYLTRANSFERASE-LIKE ACTIVITY 10

1.4.4 STRUCTURAL STUDIES OF $\gamma$-GLUTAMYLTRANSFERASE ......................... 11

1.4.5 DONOR SUBSTRATE SPECIFICITY OF $\gamma$-GLUTAMYLTRANSFERASE ..... 16

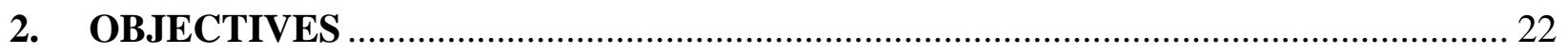

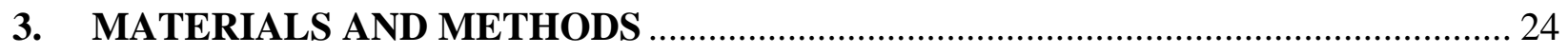

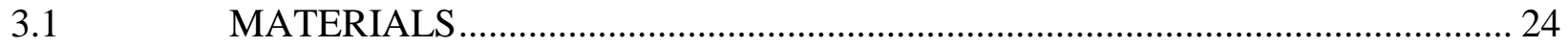


CHARACTERIZATION OF GLUTATHIONE CONJUGATES 25

3.4.1 $\gamma$-GLUTAMYL- $p$-NITROANILIDE: COLORIMETRIC ASSAY ........................ 26

3.4.2 GLUTATHIONE CONJUGATES: HPLC ASSAY ...................................... 27

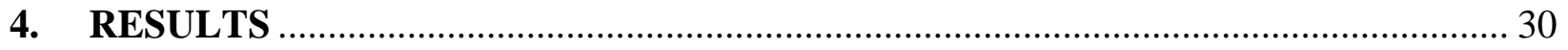

4.1. CHARACTERIZATION OF GLUTATHIONE CONJUGATES ....................... 30

4.2. SDS-PAGE ANALYSIS OF $\gamma$-GLUTAMYLTRANSFERASE ........................ 32

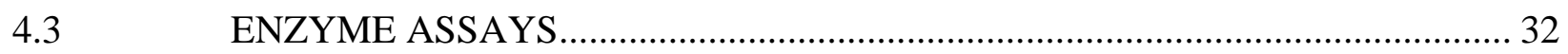

4.3.1 $\gamma$-GLUTAMYL- $p$-NITROANILIDE: COLORIMETRIC ASSAY ...................... 32

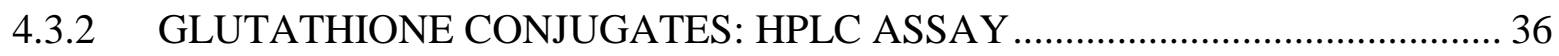

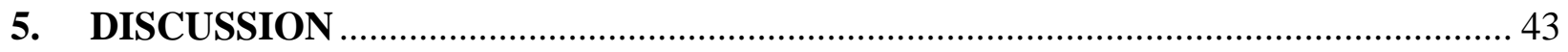

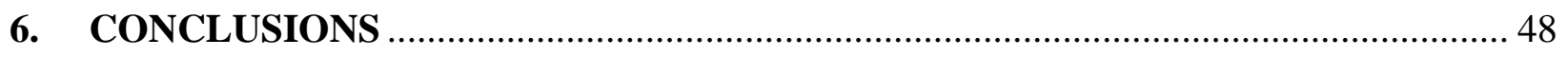

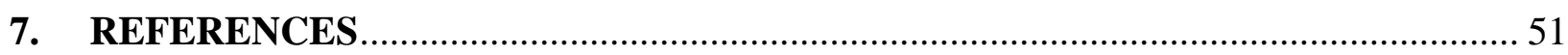

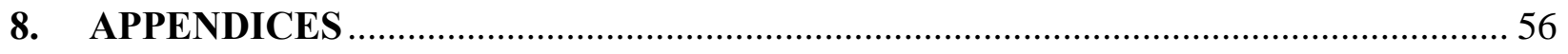

Appendix A: ESI-LC-MS spectra of the products of hydrolysis of GSH conjugates ................. 56

Appendix B: Typical progress curves of enzyme assays with GSH conjugates........................ 58

Appendix C: GSH conjugate HPLC standard curves ..................................................... 59

Appendix D: Chromatograms of enzymatic hydrolysis $(15 \mathrm{sec})$ of GSH conjugates ................. 60 


\section{LIST OF TABLES}

Table 1. Kinetic parameters of GGT1 and GGT5 (Wickham et al., 2011)............................. 20

Table 2. Donor substrate specificity of mammalian GGT: published evidence....................... 21

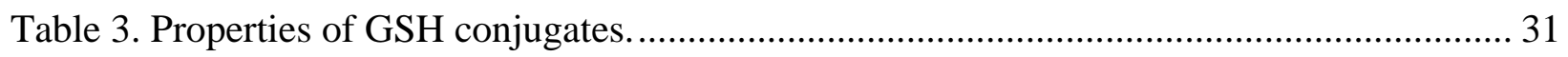

Table 4. Kinetics of GGT-catalyzed hydrolysis of GpNA. ............................................... 35

Table 5. Kinetics of GGT-catalyzed hydrolysis of GSH conjugates. .................................... 41 


\section{LIST OF FIGURES}

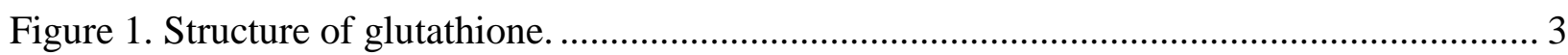

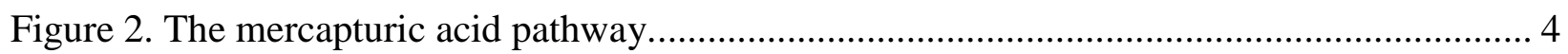

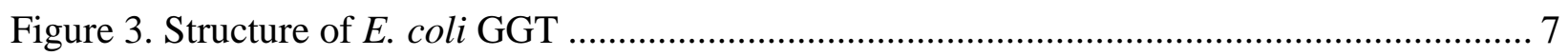

Figure 4. Enzymatic mechanism of GGT ……………........................................................ 9

Figure 5. Recognition of bound glutamate through interactions with conserved active site

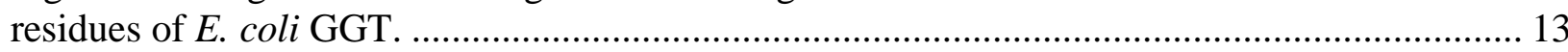

Figure 6. Multiple sequence alignment of bacterial and mammalian GGT................................. 14

Figure 7. Structures of chromogenic substrate GpNA (A) and enzymatic hydrolysis product

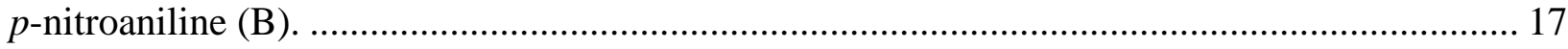

Figure 8. Structures of chemically synthesized GSH conjugates. ………………………........ 23

Figure 9. Coomassie-stained SDS-PAGE gel of GGT preparation. ............................................. 33

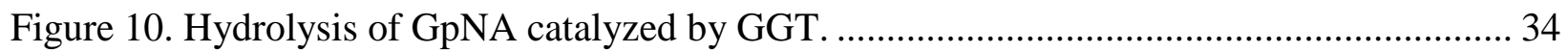

Figure 11. Representative progress curve depicting linearity of enzyme assay with GSH

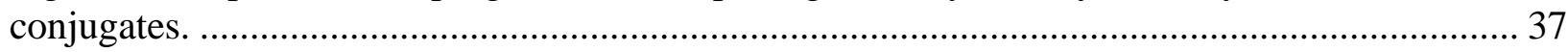

Figure 12. Representative chromatograms of the HPLC separation of enzyme assay at $0 \sec (\mathrm{A})$

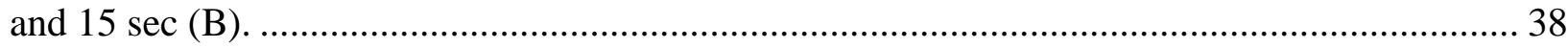

Figure 13. Hydrolysis of substrates catalyzed by GGT: DNP-GSH (A); NB-GSH (B); M-GSH (C); MA-GSH (D); MBP-GSH (E)..................................................................................... 40

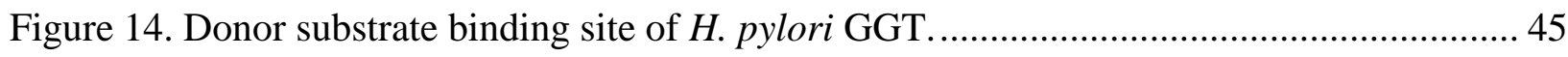

Figure 15. Multiple sequence alignment of mammalian GGT. Red boxes represent sequence identity between human, bovine, rat, mouse, pig and monkey GGT. 49 


\section{ABBREVIATIONS}

$\begin{array}{ll}\text { BSA } & \text { bovine serum albumin } \\ \text { CDNB } & \text { 1-chloro-2,4-dinitrobenzene } \\ \text { Cys, C } & \text { cysteinyl } \\ \text { Cys-Gly, CG } & \text { cysteinylglycine } \\ \text { DNP } & \text { 2,4-dinitrophenyl } \\ \text { DNP-Cys } & \text { 2,4-dinitrophenyl cysteine } \\ \text { DNP-Cys-Gly } & \text { 2,4-dinitrophenyl cysteinylglycine } \\ \text { DNP-GSH } & \text { 2,4-dinitrophenyl glutathione } \\ \text { ESI-LC-MS } & \text { electrospray ionization-liquid chromatography-mass spectrometry } \\ \text { EtOH } & \text { ethanol } \\ \text { GGL } & \gamma \text {-glutamylleukotrienase } \\ \text { GGT } & \gamma \text {-glutamyltransferase; } \gamma \text {-glutamyltranspeptidase } \\ \text { Glygly } & \text { glycylglycine } \\ \text { GpNA } & \gamma \text {-glutamyl- } p \text {-nitroanilide } \\ \text { GSH } & \text { glutathione } \\ \text { GSSG } & \text { glutathione disulfide } \\ \text { HPLC } & \text { high performance liquid chromatography } \\ \text { kDa } & \text { kilodalton } \\ K_{m} & \text { Michaelis-Menten constant; substrate concentration at half maximal } \\ \text { LT } & \text { 1-melocity } \\ \text { M } & \text { 1-menapotriene } \\ \text { M-Cys } & \\ \text { M-Cys-Gly } & \text { M-GSH }\end{array}$




$\begin{array}{ll}\text { MA } & \text { 9-methylanthracenyl } \\ \text { MA-Cys } & \text { 9-methylanthracenyl cysteine } \\ \text { MA-Cys-Gly } & \text { 9-methylanthracenyl cysteinylglycine } \\ \text { MA-GSH } & \text { 9-methylanthracenyl glutathione } \\ \text { MACl } & \text { 9-(chloromethyl)anthracene } \\ \text { MBP } & \text { 4-methylbiphenylyl } \\ \text { MBP-Cys } & \text { 4-methylbiphenylyl cysteine } \\ \text { MBP-Cys-Gly } & \text { 4-methylbiphenylyl cysteinylglycine } \\ \text { MBP-GSH } & \text { 4-methylbiphenylyl glutathione } \\ \text { MBPBr } & \text { 4-(bromomethyl)biphenyl } \\ \text { MCl } & \text { 1-(chloromethyl)naphthalene; menaphthyl chloride } \\ \text { MP } & \text { melting points } \\ \text { MS } & \text { mass spectrometry } \\ \text { m/z } & \text { mass-to-charge ratio } \\ \text { 2-NBA } & \text { 2-nitrobenzoic acid } \\ \text { NB } & \text { 4-nitrobenzyl } \\ \text { NB-Cys } & \text { 4-nitrobenzyl cysteine } \\ \text { NB-Cys-Gly } & \text { 4-nitrobenzyl cysteinylglycine } \\ \text { NB-GSH } & \text { 4-nitrobenzyl glutathione } \\ \text { NBCl } & \text { 4-nitrobenzyl chloride } \\ \text { PAH } & \text { polycyclic aromatic hydrocarbons } \\ \text { SDS-PAGE } & \text { sodium dodecyl sulfate polyacrylamide gel electrophoresis } \\ \text { TCA } & \text { trichloroacetic acid } \\ \text { UV } & \text { ultraviolet } \\ \text { V max } & \text { maximum velocity of the reaction in Michaelis-Menten kinetics } \\ & \end{array}$




\section{INTRODUCTION}

\subsection{OVERVIEW OF DETOXICATION}

The term xenobiotic refers to chemical compounds that are foreign to life, and can include drugs, pesticides, industrial chemicals and environmental pollutants (Patterson et al., 2010). Biochemical mechanisms can remove xenobiotics that have entered the body. Metabolism of exogenous and endogenous compounds through detoxication processes involving functionalization and conjugation reactions generates less toxic, more polar entities that can be readily excreted (Grant, 1991; Josephy and Mannervik 2006; Liska et al., 2006).

Cytochrome P450 enzymes are involved in the metabolism of drugs and xenobiotics, such as acetaminophen, caffeine, nicotine, and ethanol (Josephy and Mannervik 2006). These enzymes catalyze insertion of oxygen atoms into the xenobiotic substrate, to generate a metabolite that is usually less lipid soluble; in some instances, the metabolite can be more reactive than the parent compound (Gonzalez, 1988; Liska et al., 2006; Josephy and Mannervik, 2006).

Further metabolism occurs during conjugation reactions, where polar functional groups such as glucuronic acid, sulfate, or glutathione (GSH) are conjugated to the metabolites, generating a more polar compound that can be excreted (Commandeur et al., 1995; Liska et al., 2006; Omiecinski et al., 2011). However, detoxication of xenobiotics does not necessarily follow a particular order (metabolism by cytochrome P450s, then conjugation reactions); some xenobiotics and endogenous compounds are directly metabolized by conjugation with polar moieties. 


\subsection{GLUTATHIONE}

GSH ( $\gamma$-glutamylcysteinylglycine) is a major low-molecular-weight thiol found in organisms ranging from bacteria to mammals (Sies, 1999; Lu, 1999). GSH is involved in many cellular processes, such as redox homeostasis, trapping and detoxifying electrophiles, and defending the cell against oxidative stress (Lu, 1999; Josephy and Mannervik, 2006). Two structural features of GSH are its sulfhydryl group and the unusual $\gamma$-glutamyl isopeptide bond between the $\gamma$-carboxylate of glutamate and the amino group of cysteine (Figure 1). The $\gamma$ glutamyl bond protects GSH from intracellular degradation by proteases; the only enzyme known to catalyze cleavage of this bond is $\gamma$-glutamyltransferase $(\gamma$-glutamyltranspeptidase; GGT) (Lu, 1999; Josephy and Mannervik, 2006). When ionized, the sulfur atom of GSH is a good nucleophile and is able to trap electrophilic molecules (Josephy and Mannervik, 2006). Therefore, conjugation to GSH (spontaneous or enzymatic) is an important mechanism to detoxify xenobiotics; however, in some instances (e.g. certain haloalkanes), GSH conjugation can result in bioactivation of electrophiles, resulting in species that are more reactive than the parent compound (Josephy and Mannervik, 2006). GSH conjugation initiates a major pathway for the elimination of xenobiotics through the formation of mercapturic acids (Figure 2).

\subsection{THE MERCAPTURIC ACID PATHWAY}

The mercapturic acid pathway begins with the action of glutathione transferases, catalyzing xenobiotic conjugation with GSH. Hydrolysis of the $\gamma$-glutamyl isopeptide bond of GSH conjugates is catalyzed by GGT. Dipeptidases hydrolyze the resulting cysteinylglycine (Cys-Gly) conjugates (Poon and Josephy, 2012) to cysteine (Cys) conjugates, and a final Nacetylation step (Veiga de-Cunha et al., 2010) generates mercapturic acids. Mercapturic acids of 


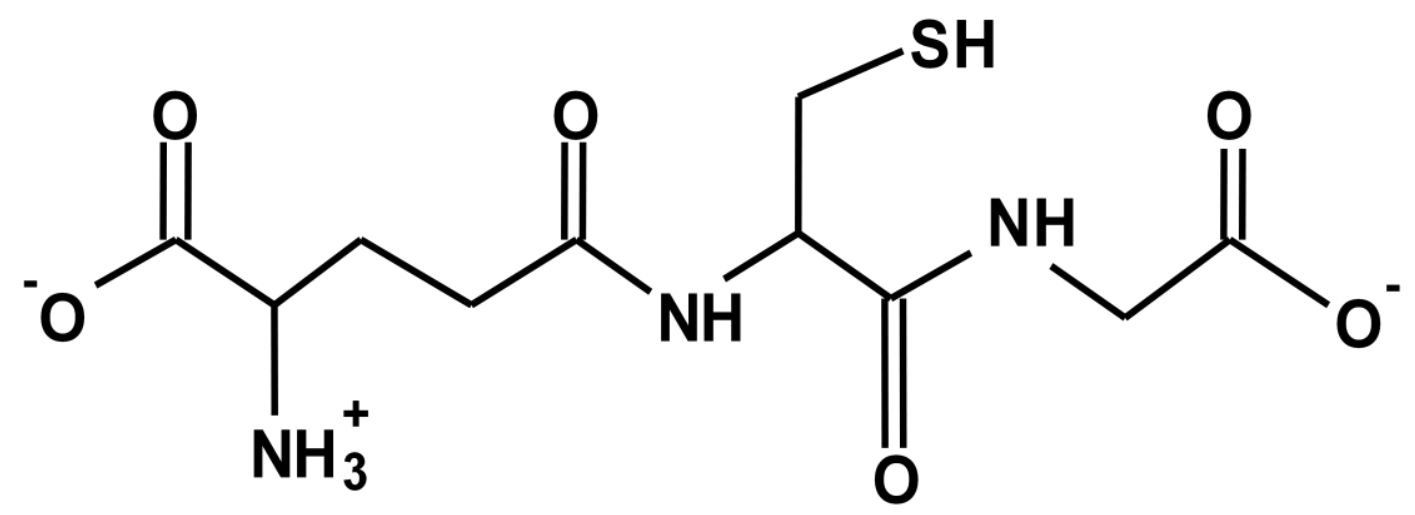

Figure 1. Structure of glutathione. 


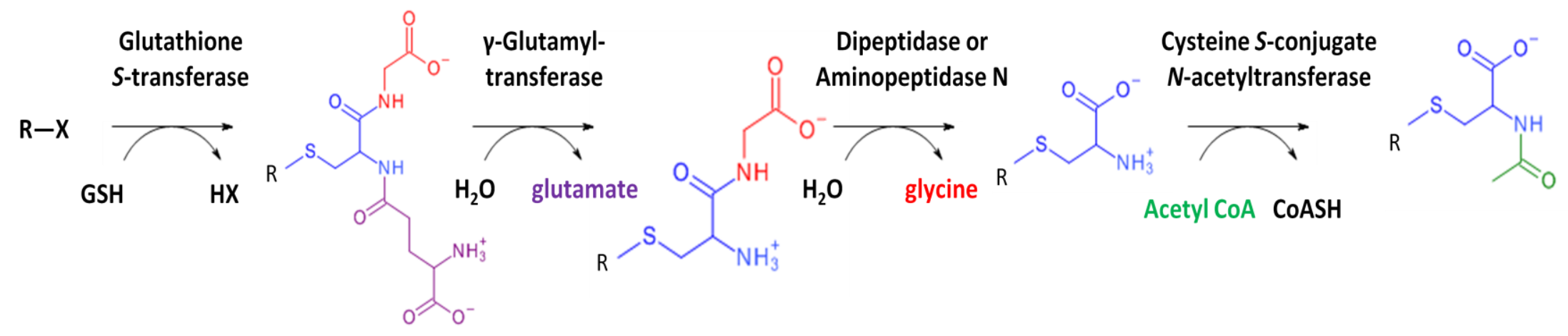

\begin{tabular}{c|} 
Xenobiotic \\
substrate
\end{tabular}

\begin{tabular}{|l|}
\hline Glutathione \\
S-conjugate
\end{tabular}

\begin{tabular}{|c|}
\hline $\begin{array}{c}\text { Cysteinylglycine } \\
\text { S-conjugate }\end{array}$ \\
\hline
\end{tabular}

\section{Cysteine $S$-conjugate}
$N$-Acetylcysteine $S$-conjugate

Figure 2. The mercapturic acid pathway.

Steps are conjugation with glutathione, hydrolysis of the $\gamma$-glutamyl isopeptide bond of the GSH conjugate, hydrolysis of the $\alpha$ peptide bond of the Cys-Gly conjugate, and N-acetylation of the Cys conjugate. $\mathrm{R}$ represents a xenobiotic (e.g. 1-chloro-2,4dinitrobenzene). 
aromatic xenobiotics, such as benzene, toluene, xylene and styrene have been detected in human urine through high performance liquid chromatography (HPLC)-mass spectrometry (MS) analyses (Sabatini et al., 2008; Reska et al., 2010); naphthalene- and benzo[a]pyrene-derived mercapturic acids have also been detected in the urine of rodents (Stillwell et al., 1982; Yang et al., 1998). Aromatic and polycyclic aromatic hydrocarbons (PAH) are toxicologically relevant, potentially carcinogenic or mutagenic xenobiotics, to which humans are exposed (Sabatini et al., 2008; Reska et al., 2010). The focus of this study is the enzyme GGT, and its role in the GSHdependent metabolism of monocyclic and polycyclic aromatic xenobiotics.

\section{$1.4 \quad \gamma$-GLUTAMYLTRANSFERASE}

GGT (EC 2.3.2.2) is found in organisms ranging from bacteria to mammals (Castonguay et al., 2007). The enzyme was first identified when Binkley and Nakamura noted an activity present in the tissues of rat kidney, liver, spleen, heart, skeletal muscle, testicles, and thymus that could hydrolyze GSH (Binkley and Nakamura, 1948). In mammals, the enzyme is found mainly in the kidney (Tate and Meister, 1981; Ikeda and Taniguchi, 2005). Mammalian GGT is a membrane-bound heterodimeric glycoprotein; the heavy subunit of GGT anchors the protein to the membrane and the light subunit contains the catalytic site of the enzyme (Castonguay et al., 2007). GGT acts in the metabolism of xenobiotics and endogenous GSH conjugates, in GSH homeostasis, in cysteine recovery, and it is often used as a biomarker of liver damage (Lieberman et al., 1996; Ikeda and Taniguchi, 2005; Castonguay et al., 2007; Heisterkamp et al., 2008; Wickham et al., 2011). GGT-knock-out mice had elevated levels of GSH in the urine (15 $\mathrm{mM})$ and plasma $(175 \mu \mathrm{M})$; GSH levels of WT mice in the urine and plasma were $6 \mu \mathrm{M}$ and 28 $\mu \mathrm{M}$, respectively (Lieberman et al., 1996). This indicates the importance of GGT in GSH 
homeostasis through degradation of the tripeptide (Lieberman et al., 1996). Plasma cysteine levels of WT and GGT-knock-out mice were $12 \mu \mathrm{M}$ and $2 \mu \mathrm{M}$, respectively (Lieberman et al., 1996), demonstrating that GGT is significant in cysteine recovery by initiating the cleavage of GSH into its constituent amino acids (Lieberman et al., 1996). Serum GGT is "mainly derived from the liver" (Okada et al., 2006). Elevated levels of serum GGT usually indicates hepatic damage, allowing for the use of GGT as a biomarker of liver damage (Okada et al., 2006; Heisterkamp et al., 2008). GGT exhibits an $\alpha \beta \beta \alpha$ fold (Okada et al., 2006), as shown in Figure 3.

\subsubsection{DONOR AND ACCEPTOR SUBSTRATES}

GGT utilizes two types of substrates: donor substrates contain the $\gamma$-glutamyl isopeptide bond to be cleaved, and acceptor substrates receive the hydrolyzed $\gamma$-glutamyl moiety. Hanes and colleagues showed that GSH and $\gamma$-glutamyl peptides could act as donor substrates; water, amino acids, and $\gamma$-glutamyl peptides could serve as acceptor substrates (Hanes et al., 1950; Hanes et al., 1952). Sheep kidney GGT was incubated with GSH, $\gamma$-glutamyl peptides and amino acids; the enzymatic $\gamma$-glutamyl products were separated by paper chromatography and visualized with ninhydrin. The formation of $\gamma$-glutamyl products indicated a transpeptidation reaction, where the $\gamma$-glutamyl moiety of the donor substrate (GSH, $\gamma$-glutamyl peptide) was transferred to an acceptor substrate (amino acid or $\gamma$-glutamyl peptide). In addition, GGT incubated with GSH alone produced a small amount of glutamate, suggesting that a hydrolysis reaction also occurs, with water as the acceptor substrate (Hanes et al., 1950, Hanes et al., 1952). The transpeptidation reaction is thought to occur when high concentrations of amino acids or dipeptides are present (Tate and Meister, 1974). In a standard assay (described in section 1.4.5) with donor substrate $\gamma$ glutamyl-p-nitroanilide (GpNA) and various acceptor substrates, the highest specific activities 


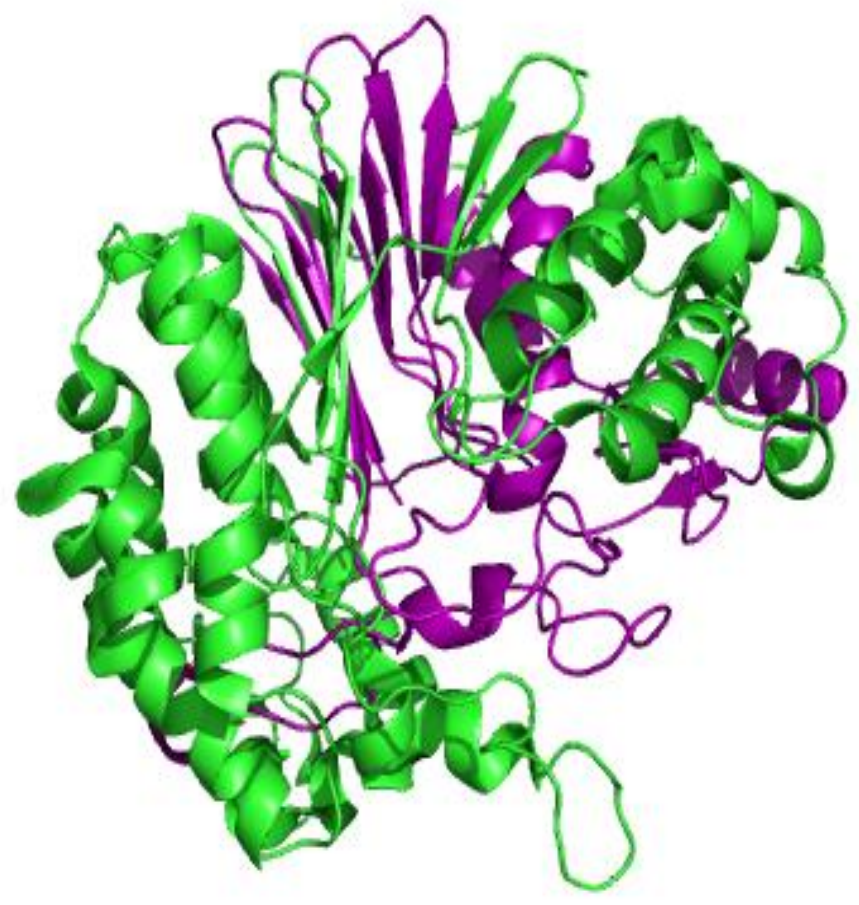

Figure 3. Structure of $E$. coli GGT.

PDB File 2DBU. The heavy and light subunits are shown in green and purple, respectively. The protein exhibits an $\alpha \beta \beta \alpha$ fold. Figure was generated with PyMOL (The PyMOL Molecular Graphics System, Version 1.3, Schrödinger, LLC). 
for rat kidney GGT were observed with glycylglycine (glygly; $110 \mu \mathrm{mol} / \mathrm{min} / \mathrm{mg}$ ), glutamine (37 $\mu \mathrm{mol} / \mathrm{min} / \mathrm{mg}$ ) and methionine $(35 \mu \mathrm{mol} / \mathrm{min} / \mathrm{mg}$ ) as acceptor substrates (Tate and Meister, 1974). The generation of glutamate through the hydrolysis reaction is thought to be the predominant reaction occurring at physiological $\mathrm{pH}$ (Wickham et al., 2011). Autotranspeptidation may occur with high concentrations of donor substrates or when no acceptor substrate is present (Tate and Meister, 1974; Morin et al., 2006; Wickham et al., 2011).

\subsubsection{ENZYMATIC MECHANISM}

The catalytic cycle of GGT follows a ping-pong mechanism (Figure 4), similar to the type of enzymatic mechanism observed with serine proteases (Tate and Meister, 1974; Morin et al., 2006). One substrate binds to the enzyme and one product is released; a second substrate binds and a second product is released, resembling a ping pong ball moving back and forth. In the first step of the reaction cycle of GGT, the $\gamma$-glutamyl moiety of the donor substrate (GSH) reacts with a hydroxyl group in the active site of the enzyme to generate a tetrahedral acylenzyme intermediate (Tate and Meister, 1974; Wickham et al., 2011). In the case of the E. coli GGT, the catalytic residue has been identified as Thr391, the N-terminal residue of the light subunit (Inoue et al., 2000; Okada et al., 2006). Release of the donor in its free amine form (e.g., cysteinylglycine) from the tetrahedral intermediate produces the covalent acyl-enzyme $(\gamma$ glutamyl enzyme) intermediate (Tate and Meister, 1974; Wickham et al., 2011). Subsequent acyl transfer of the $\gamma$-glutamyl moiety to an acceptor substrate, such as water or a dipeptide, releases glutamate or a $\gamma$-glutamyl dipeptide, respectively, and completes the reaction cycle (Tate and Meister, 1974; Castonguay et al., 2003; Morin et al., 2006; King et al., 2009; Wickham et al., 2011). 


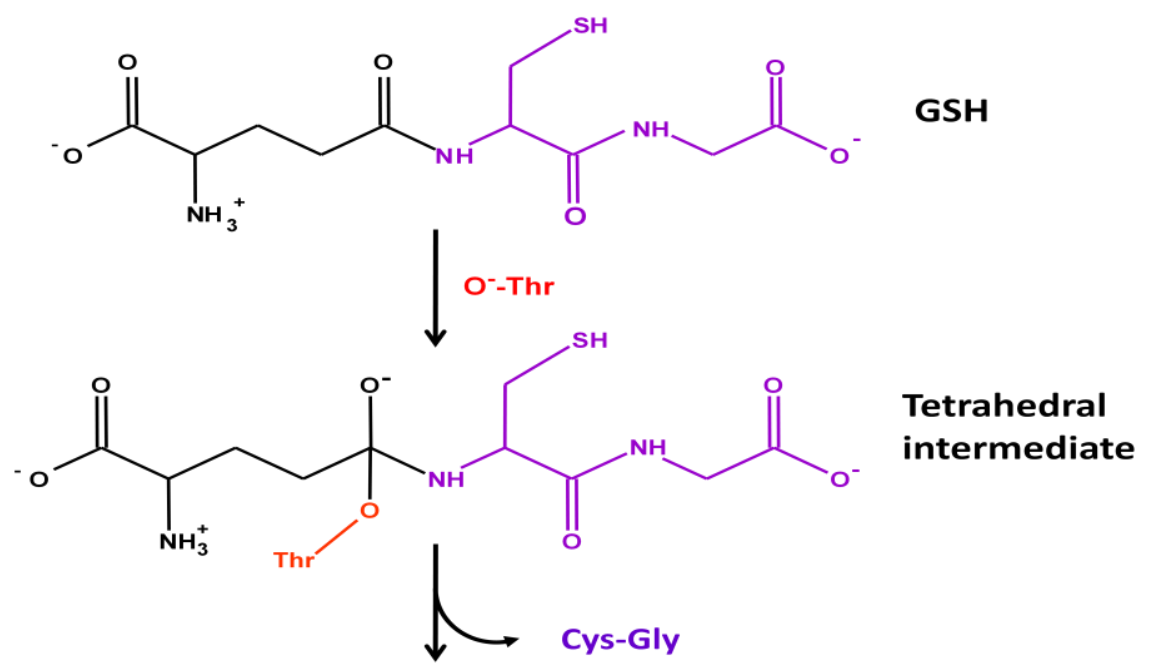<smiles>NC(CCC(=O)O[In])C(=O)O</smiles><smiles>CCCCCCCCCCCCCCCCCCCCCCCCCCCCCCCCCCCCCCCCCCCCCCCCCCCC(=O)OCC(=O)O</smiles>

Figure 4. Enzymatic mechanism of GGT. GSH is shown as the donor substrate. The hydroxyl group of the catalytic Thr nucleophile attacks the gamma-glutamyl moiety forming a tetrahedral intermediate. Formation of the gamma-glutamyl-enzyme intermediate occurs when the Cys-Gly moiety leaves. The gamma-glutamyl group is then transferred to an acceptor substrate, either water or a dipeptide (glycylglycine) forming glutamate, and gamma-glutamylglycylglycine, respectively. 


\subsubsection{OTHER ENZYMES WITH $\gamma$-GLUTAMYLTRANSFERASE-LIKE ACTIVITY}

Heisterkamp and colleagues identified human GGT-rel, a 2.4 kB cDNA that displayed 39.5\% amino acid sequence identity to GGT (Heisterkamp et al., 1991). This group also identified sequences of GGT-rel that could represent the heavy and light chains, and a transmembrane domain, common to GGT enzymes. Enzyme produced from transfectants overexpressing human GGT-rel was used in assays to determine its donor substrate specificity; substrates tested were GSH, leukotriene (LT) $\mathrm{C}_{4}$, and the chromogenic substrates GpNA and $\gamma$ glutamyl-4-methoxy-2-naphthylamide. Assays with GSH and $\mathrm{LTC}_{4}$ were monitored by HPLC (LTD 4 formation and GSH degradation); chromogenic substrates were analyzed through spectrophotometry. It was concluded that human GGT-rel is able to hydrolyze $\mathrm{LTC}_{4}$ and GSH; however, no activity was observed with GpNA or $\gamma$-glutamyl-4-methoxy-2-napthylamide as donor substrates. This finding indicates that human GGT-rel can cleave physiological donor substrates of GGT, but is unable to hydrolyze chromogenic donor substrates. The researchers concluded that even though GGT-rel is structurally similar to GGT, it exhibits distinct substrate specificity (Heisterkamp et al., 1991).

Carter and colleagues studied GGT-knock-out mice that were generated by embryonic stem cell technology (Lieberman et al., 1996; Carter et al., 1997). A recombinant plasmid carrying the mouse GGT-knock-out gene was transfected into embryonic stem cells; transformed embryonic stem cells were inserted into mouse blastocysts; blastocysts were implanted into a female mouse (Lieberman et al., 1996). Chimeras were mated with wild-type mice, and the heterozygous (+/-) offspring were interbred, producing homozygous (-/-) GGT-knock-out mice. Phenotypically, GGT-knock-out mice (-/-) were about half the weight of wild-type mice, developed cataracts, were sexually immature, and died between 10 and 18 weeks (Lieberman et 
al., 1996). Tissue homogenates from GGT-knock-out mice (-/-) were incubated with $\mathrm{LTC}_{4}, \mathrm{GSH}$, GSSG, GpNA and $\gamma$-glutamyl-4-methoxy-2-naphthylamide. HPLC was used to monitor the reactions with $\mathrm{LTC}_{4}, \mathrm{GSH}$ and GSSG; spectrophotometric analysis was used for GpNA and $\gamma$ glutamyl-4-methoxy-2-naphthylamide. It was concluded that there was enzyme activity present that was able to cleave $\mathrm{LTC}_{4}$, and was named $\gamma$-glutamylleukotrienase (GGL) (Carter et al., 1997). Other physiological donor substrates such as GSH, GSSG, or chromogenic donor substrates such as GpNA and $\gamma$-glutamyl-4-methoxy-2-naphthylamide were not hydrolyzed by GGL (Carter et al., 1997).

\subsubsection{STRUCTURAL STUDIES OF $\gamma$-GLUTAMYLTRANSFERASE}

Multiple sequence alignments of rat, human, pig, and E. coli GGTs and human GGT-rel were used to identify conserved active site residues that could be critical to enzyme function. Arg107 and Asp423 of human GGT were the conserved active site residues selected for amino acid substitution studies (Ikeda et al. 1993; 1995). Site-directed mutagenesis variants R107Q, R107H, and R107K of human GGT were transfected into COS-1 cells. Variants of D423A and D423E of human GGT were expressed in a baculovirus insect cell system. Enzyme activity was measured with the standard assay (section 1.4.5). Human GGT variants R107H and R107Q displayed no detectable activity; R107K had $0.87 \%$ activity of the WT enzyme; D423A and D423E had specific activities of $0.0035 \mu \mathrm{mol} / \mathrm{min} / \mathrm{mg}$ and $0.059 \mu \mathrm{mol} / \mathrm{min} / \mathrm{mg}$, respectively, compared to WT specific activity of 440 . In addition, the $K_{m}$ for R107K was 8.4-fold greater than WT; 2000- and 5000- fold increases in $K_{m}$ were observed for D423A and D423E, respectively. It was concluded on the basis of huge reductions in activity, that these residues are essential for 
enzyme function, and are probably involved in donor substrate recognition through electrostatic interactions with the $\alpha$-amino and $\alpha$-carboxyl groups of the $\gamma$-glutamyl substrate (Ikeda et al. $1993 ; 1995)$.

The crystal structures of E. coli GGT in complex with GSH, and E. coli GGT bound to glutamate, were studied to gain insight into substrate recognition (Okada et al. 2006). The $\gamma$ glutamyl moiety was buried within the core of the enzyme. There is slight solvent accessibility at the site of the $\gamma$-glutamyl bond. The Cys-Gly moiety is solvent exposed. The residues mentioned above (Arg107 and Asp423 of human GGT), in addition to others, were involved in hydrogen bonds and electrostatic interactions with the $\gamma$-glutamyl donor substrate; this is depicted in Figure 5. The E. coli GGT residues involved in stabilizing the $\alpha$-amino group of the donor substrate are Asn411, Gln430, and Asp433 (Asp 423 of human GGT mentioned above); the $\alpha$-carboxyl group is recognized by Arg114 (Arg107 of human GGT), Ser462, and Ser463; and the $\gamma$-carbonyl is stabilized through interactions with Gly483 and Gly484. All of these residues are located in the light subunit, except for Arg114. A substrate-binding loop was also identified; Tyr444 of the loop was proposed to hydrogen bond to Asn411 in order to shield the active site from solvent. The residues involved in stabilizing the $\gamma$-glutamyl moiety of the donor substrate are conserved across E. coli, H.pylori, human, rat and bovine GGTs (Figure 6) (Okada et al. 2006).

Morrow and colleagues solved the crystal structure of $H$. pylori GGT bound to glutamate, and of the catalytically-defective site-directed mutagenesis variant T380A of $H$. pylori GGT complexed to 4-nitrobenzyl glutathione (NB-GSH) (Morrow et al., 2007). An "extensive hydrogen bond network" for the recognition of the donor substrate was also observed for $H$. pylori GGT, and a solvent-exposed cavity adjacent to the $\gamma$-glutamyl binding site accommodated the Cys-Gly moiety. The researchers aimed to explore interactions with the Cys-Gly moiety 


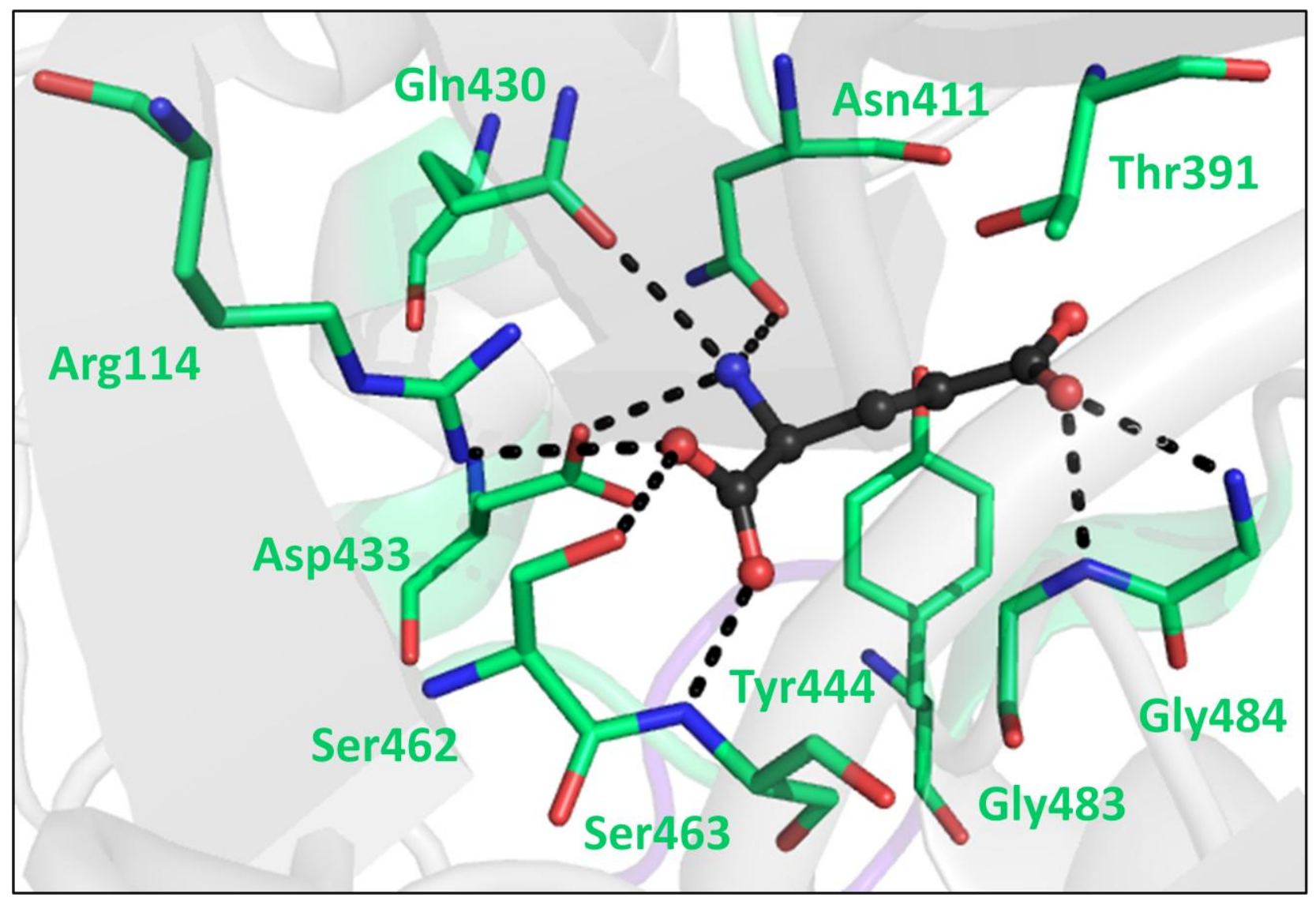

Figure 5. Recognition of bound glutamate through interactions with conserved active site residues of $E$. coli GGT.

PDB file 2DBX. Conserved active site residues as green sticks; glutamate (black) is shown in ball-and-stick representation. Oxygen and nitrogen atoms are depicted in red and blue, respectively. Dashed lines represent interactions between conserved active site residues and bound glutamate. Figure was generated with PyMOL (The PyMOL Molecular Graphics System, Version 1.3, Schrödinger, LLC). 

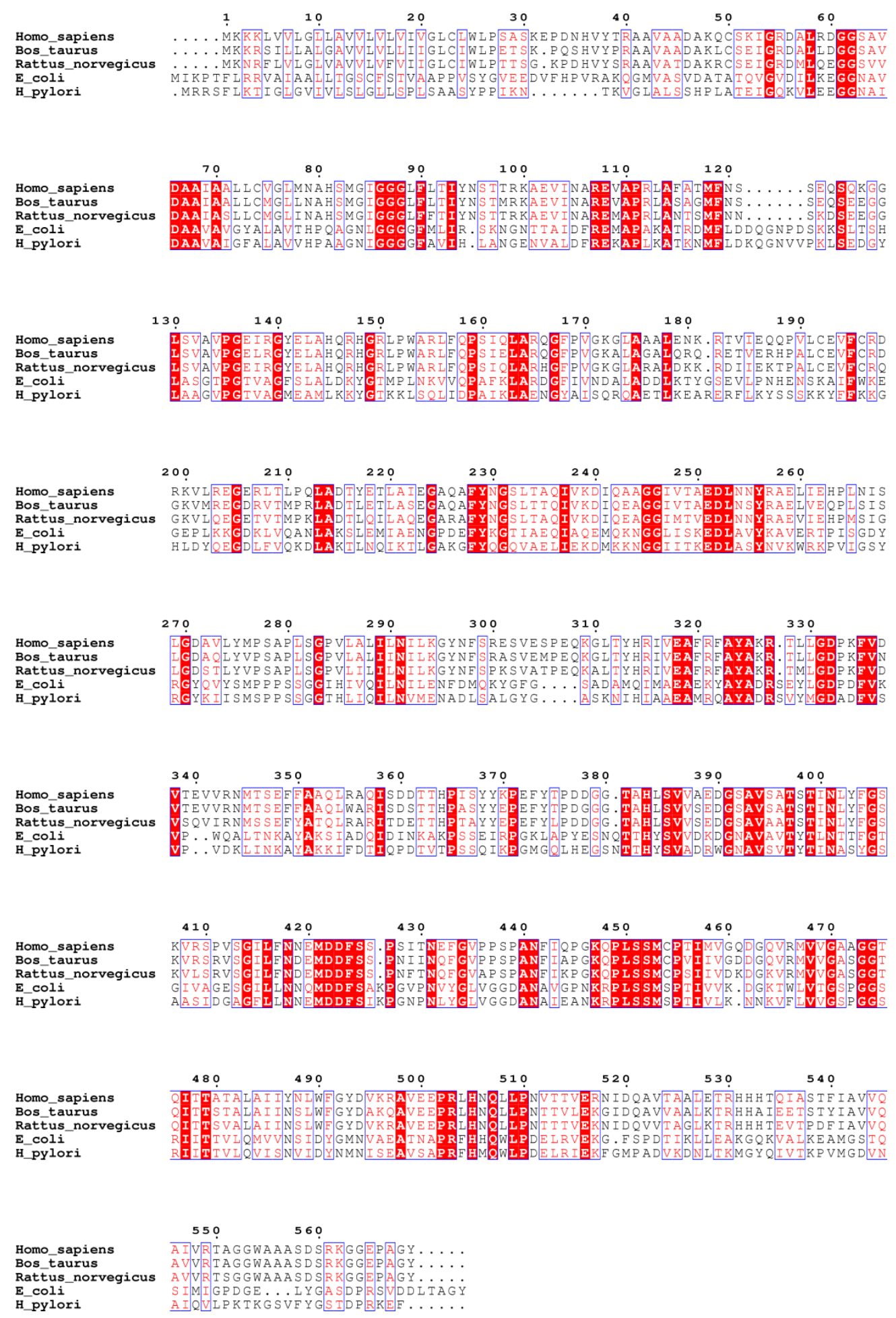

Figure 6. Multiple sequence alignment of bacterial and mammalian GGT. Positions (corresponding to human GGT) 107, 401, 420, 423, 451, 452, 473 and 474 represent conserved active site residues; position 433 represents the conserved aromatic gating residue; position 381 indicates the conserved nucleophilic residue. 
using NB-GSH bound to variant $H$. pylori GGT; however, weak electron density was observed past the $\gamma$-glutamyl moiety, so the remainder of the substrate was not well defined. The location of the 4-nitrobenzyl group could not be discerned, presumably due to its "conformational flexibility", and "may account for the substrate binding permissiveness of the enzyme". The same is probably true of the mammalian enzymes (Hu et al., 2012), although crystal structures are not yet available. In addition, Morrow and colleagues suggested that the Cys-Gly moiety might overlap with the acceptor substrate binding site of $H$. pylori GGT (Morrow et al., 2007).

Since substrate is thought to bind deep within the donor substrate binding pocket (consistent with E. coli GGT), the researchers proposed that the substrate binding loop undergoes a conformational change to allow substrate entry into the active site (Morrow et al., 2007). The gating residue (Tyr444) of H. pylori GGT is believed to H-bond to Asn400 (conserved active site residue) and performs a similar function as in E. coli GGT. To investigate further the importance of the substrate binding loop, amino acid substitutions of the gating residue and residues involved in forming the hydrogen bond network stabilizing the gating residue (Gln506, Asn431, Asp421) were performed, and enzyme activity was measured with the standard assay (section 1.4.5). Y433A and Y433F variants of $H$. pylori GGT exhibited 25 -fold and 1.25 -fold decreases, respectively, in activity; Q506A, N431S and D421S displayed 27, 40 and 35-fold decreases, respectively. This result indicates that the gating residue, which must be an aromatic residue, and the residues involved in its stabilization, are important in shielding the active site from solvent and allowing substrate to enter the active site, which could contribute to enzyme efficiency.

Since there are no crystal structures available for mammalian GGT, human GGT was modelled based on E. coli GGT, and molecular dynamics simulations were used to probe the donor and acceptor substrate binding sites (Hu et al., 2012). Computationally, the GSH donor 
substrate was docked into the enzyme active site, and "fluctuations" between enzyme alone and enzyme bound to substrate were observed. The model showed the $\gamma$-glutamyl moiety of GSH buried deep within the donor substrate binding pocket, and an "extensive hydrogen bonding network" between the $\gamma$-glutamyl moiety of the donor substrate and conserved active site residues. Furthermore, there is a flexible substrate binding loop with a gating residue (Phe 433) that is also involved in donor substrate recognition. The exposed Cys-Gly moiety is believed to point towards the acceptor substrate site, which is less conserved than the donor substrate binding site, and is mostly composed of polar residues. It was suggested that the glycyl carboxylate moiety of GSH is stabilized by an electrostatic interaction with Lys562, and a hydrogen bond with Tyr403 of the acceptor substrate binding site.

From these structural studies, it can be concluded that the conserved substrate binding loop containing the aromatic gating residue is important for substrate entry into the active site, the $\gamma$-glutamyl moiety of the donor substrate is recognized by conserved active site residues, and the Cys-Gly moiety is solvent exposed, and either overlaps or points towards the acceptor substrate site of GGT.

\subsubsection{DONOR SUBSTRATE SPECIFICITY OF $\gamma$-GLUTAMYLTRANSFERASE}

The most common spectrophotometric assay to measure GGT activity in mammalian tissues uses the chromogenic substrate, GpNA (Orlowski and Meister, 1963; Meister et al., 1981). GGT hydrolyzes the $\gamma$-glutamyl isopeptide bond of GpNA; $p$-nitroaniline product formation can be monitored spectrophotometrically at $410 \mathrm{~nm}$. The assay conditions are usually $1 \mathrm{mM}$ GpNA (donor substrate), $20 \mathrm{mM}$ glygly (acceptor substrate) and $100 \mathrm{mM}$ Tris- $\mathrm{HCl}(\mathrm{pH}$ 8.0). The structures of GpNA and $p$-nitroaniline are shown in Figure 7. Other chromogenic 
A)<smiles>[NH3+]C(CCC(=O)Nc1ccc([N+](=O)[O-])cc1)C(=O)[O-]</smiles>

B)

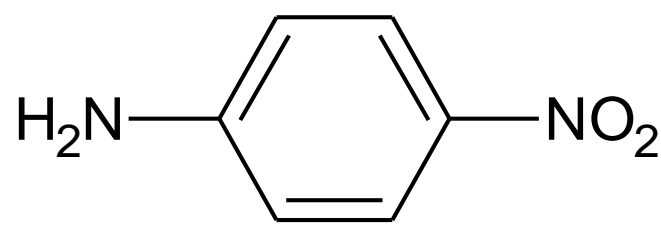

Figure 7. Structures of chromogenic substrate GpNA (A) and enzymatic hydrolysis product p-nitroaniline (B). 
substrates that have been used to measure GGT activity include a GpNA derivative, $\gamma$-glutamyl3-carboxy-4-nitroanilide, and $\gamma$-glutamyl-2-naphthylamide (Shaw et al., 1977; Smith et al., 1979). A fluorescence assay uses $\gamma$-glutamyl-7-amino-4-methylcoumarin as the donor substrate (Smith et al., 1979).

Few studies have investigated the donor substrate specificity of GGT. Cook and colleagues measured the donor substrate specificity of rat kidney GGT (Cook et al., 1987). The researchers tested a wide range of small $\gamma$-glutamyl compounds, and noted that the $K_{m}$ and $\mathrm{V}_{\max }$ values varied from $36 \mu \mathrm{M}$ to $1.25 \mathrm{mM}$, and from 1.03 to $26 \mu \mathrm{mol} / \mathrm{min} / \mathrm{mg}$, respectively. It is commonly believed that the Michaelis-Menten constant is simply a measure of enzyme-substrate binding affinity; however, it can also reflect the kinetics of the subsequent product formation steps (Northrop, 1998). Cook and colleagues speculated that differences in $K_{m}$ were not only a direct reflection of affinity for the enzyme, but were also due to changes of the rate constant $\mathrm{k}_{3}$, which is involved in the conversion of the initial donor substrate-enzyme complex to the $\gamma$ glutamyl-enzyme intermediate. Differences in $\mathrm{V}_{\max }$ were thought to be due to the electronwithdrawing ability of the adduct; faster hydrolysis occurred with more electron-withdrawing adducts "due to destabilization of the $\gamma$-peptide bond", which allows for faster formation of the $\gamma$ glutamyl enzyme intermediate. They concluded that $\gamma$-glutamyl moiety of the donor substrate is the primary determinant recognized; however, the chemical nature of the adduct was important in determining the rate of the formation of the $\gamma$-glutamyl-enzyme intermediate, which was important in reflecting differences of $K_{m}$ and $\mathrm{V}_{\max }$. Nevertheless, no direct correlation between the observed $K_{m}$ and the adduct structure of the donor substrate was made.

Recently, Wickham and colleagues have further investigated the donor substrate specificity of recombinant human GGT (GGT1) and human $\gamma$-glutamyl leukotrienase (GGT5), 
expressed in Pichia pastoris, through development of a novel coupled assay to quantitate the release of glutamate from several donor substrates (Wickham et al., 2011). The kinetic parameters from this study are summarized in Table 1. Interestingly, no enzymatic activity was detected with $\gamma$-glutamylleucine as a substrate for GGT5. Similar $K_{m}$ values were observed for both GGT1 and GGT5 with GSH, LTC 4 , NB-GSH and S-methylglutathione. Higher $K_{m}$ values were observed with glutathionesulfonic acid and $\gamma$-glutamylleucine for GGT1 and with GSSG and glutathionesulfonic acid for GGT5. Similar $\mathrm{V}_{\max }$ values were noted for all substrates with both enzymes, but they were 25-fold lower for GGT5. Lower catalytic efficiencies were observed for GGT1 with $\gamma$-glutamylleucine and for GGT5 with glutathionesulfonic acid. The researchers concluded that the "substrate binding pockets of human GGT1 and human GGT5 both bind $\gamma$-glutamyl substrates, but have some unique characteristics".

Previous studies of the donor substrate specificity of mammalian GGT are summarized in Table 2. Although the number of substrates tested is substantial, few studies tested more than two substrates, and there was little or no correlation between kinetics and substrate structure. In addition, the majority of substrates tested were chromogenic donor substrates, which are less relevant to the mercapturic acid pathway since these compounds are not endogenous or xenobiotic GSH conjugates. 
Table 1. Kinetic parameters of GGT1 and GGT5 (Wickham et al., 2011)

\begin{tabular}{|c|c|c|c|c|c|c|}
\hline \multirow[b]{3}{*}{ Substrate } & \multicolumn{6}{|c|}{ Enzyme } \\
\hline & \multicolumn{3}{|c|}{ GGT1 } & \multicolumn{3}{|c|}{ GGT5 } \\
\hline & $\mathbf{K}_{\mathrm{m}}$ & $\mathbf{V}_{\max }$ & $\mathbf{V}_{\max } / \mathbf{K}_{\mathrm{m}} \mathbf{E}_{\mathrm{t}}$ & $\mathbf{K}_{\mathrm{m}}$ & $\mathbf{V}_{\max }$ & $\mathbf{V}_{\max } / \mathbf{K}_{\mathrm{m}} \mathbf{E}_{\mathrm{t}}$ \\
\hline$\overline{\mathrm{GSH}}$ & 11 & 6 & 0.6 & 11 & 0.2 & 0.02 \\
\hline GSSG & 9 & 6 & 0.7 & 43 & 0.3 & 0.01 \\
\hline $\mathrm{LTC}_{4}$ & 11 & 5 & 0.5 & 10 & 0.2 & 0.02 \\
\hline NB-GSH & 13 & 6 & 0.5 & 15 & 0.3 & 0.02 \\
\hline S-methylglutathione & 10 & 6 & 0.6 & 18 & 0.2 & 0.01 \\
\hline $\begin{array}{l}\text { Glutathionesulfonic } \\
\text { acid }\end{array}$ & 35 & 6 & 0.2 & 75 & 0.2 & 0.002 \\
\hline$\gamma$-glutamylleucine & 33 & 3 & 0.01 & NA & NA & NA \\
\hline
\end{tabular}

$\mathrm{NA}$ - no enzymatic activity detected

Units: $\mathrm{K}_{\mathrm{m}}-\mu \mathrm{M} ; \mathrm{V}_{\max }-\mu \mathrm{M} / \mathrm{min} / \mathrm{nM} ; \mathrm{V}_{\max } / \mathrm{K}_{\mathrm{m}} \mathrm{E}_{\mathrm{t}}-\min ^{-1} \mathrm{nM}^{-1}$ 
Table 2. Donor substrate specificity of mammalian GGT: published evidence.

\begin{tabular}{|c|c|}
\hline Enzyme & Donor substrate \\
\hline $\begin{array}{l}\text { Recombinant human }\left(P . \text { pastoris }^{1,2} ;\right. \\
\text { commercial porcine kidney }{ }^{3} \text {, bovine kidney }{ }^{4} \text {; } \\
\text { rat kidney }{ }^{23}\end{array}$ & GSH \\
\hline $\begin{array}{l}\text { Recombinant human }(P . \text { pastoris })^{2} ; \\
\text { commercial porcine kidney }\end{array}$ & $\mathrm{LTC}_{4}$ \\
\hline $\begin{array}{l}\text { Recombinant human }(P . \text { pastoris })^{2} \text {, rat } \\
\text { kidney }^{23}\end{array}$ & $\begin{array}{l}\text { GSSG, NB-GSH, S-methylglutathione, } \\
\text { glutathionesulfonic acid, } \gamma \text {-glutamylleucine }\end{array}$ \\
\hline Commercial bovine kidney $^{5}$ & S-nitrosoglutathione \\
\hline $\begin{array}{l}\text { Recombinant human }(P \text {. pastoris })^{1,7} ; \text { human } \\
\text { liver }^{6} \text {, neutrophils }{ }^{9}, \text { kidney }^{12}, \text { serum }^{16} ; \text { rat } \\
\text { kidney }^{8,23} \text {,pancreas }{ }^{11} \text {, deciduoma }{ }^{13} ; \text { bovine } \\
\text { liver }^{10}, \text { parotid }^{14}, \text { ciliary body }^{15} ; \text { hog kidney }^{16}\end{array}$ & GpNA \\
\hline Human testis $^{17} ;$ human serum ${ }^{16} ;$ hog kidney ${ }^{16}$ & $\gamma$-glutamyl-3-carboxy-4-nitroanilide \\
\hline Rat liver $^{18,19,20}$, biliary tract ${ }^{18}$, kidney $^{23}$ & $\gamma$-glutamyl-7-amino-4-methylcoumarin \\
\hline Rat liver $^{20}$ & $\gamma$-glutamyl-2-naphthylamide \\
\hline Commercial equine kidney ${ }^{21}$ & $\gamma$-glutamyl-D,L-phenylthioglycylglycine \\
\hline Rat kidney $^{8}$ & $\gamma$-glutamic acid- $p$-nitroanilide methyl ester \\
\hline Sheep kidney ${ }^{22}$ & $\alpha$-methyl-5-glutamyl- $\alpha$-aminobutyrate \\
\hline Rat kidney $^{23}$ & $\begin{array}{l}\text { Glutamine, } \gamma \text {-glutamylethylamine, } \\
\gamma \text {-glutamyl-t-butylamine, } \gamma \text {-glutamyl-p- } \\
\text { methylanilide }\end{array}$ \\
\hline
\end{tabular}

References: Castonguay et al., 2007 ${ }^{1}$; Wickham et al., 2011²; Orning and Hammarstrom, $1982^{3}$; Del Corso et al., 2006 ${ }^{4}$; Angeli et al., 20095; Huseby et al., 1977 ; Wickham et al., 2012 Lherbet et al., $2003^{8}$; Sener and Yardimci, $2005^{9}$; Furukawa et al., $1983^{10}$; Takahashi et al., $1982^{11}$; Miller et al., $1976^{12}$; Tarchand, $1984^{13}$; Hata et al., $1981^{14}$; Das and Shichi, $1979^{15}$; Shaw et al., $1977^{16}$; Arai et al., $1990^{17}$; Ding et al., $1981^{18}$; Ding et al., $1980^{19}$; Smith et al., $1979^{20}$; Vergauwen et al., $2009^{21}$; Karkowsky et al., $1976^{22}$; Cook et al., $1987^{23}$ 


\section{OBJECTIVES}

To date, the donor substrate specificity of GGT is poorly understood. Standard assays used to measure GGT activity use convenient chromogenic substrates that are less relevant to the mercapturic acid pathway. Therefore, we aimed to enhance characterization of GGT through kinetic studies with GSH conjugates. Because few such conjugates are commercially available, we prepared several GSH conjugates (Figure 8): 2,4-dinitrophenyl glutathione (DNP-GSH), 4nitrobenzyl glutathione (NB-GSH), 1-menaphthyl glutathione (M-GSH), 9-methylanthracenyl glutathione (MA-GSH), and 4-methylbiphenylyl glutathione (MBP-GSH), representative of detoxication products of aromatic xenobiotics. HPLC separation with UV detection was used for quantitation. As a basis for reference, the standard chromogenic substrate, GpNA, was also tested. Enzyme kinetics of GGT was studied to investigate the structural factors affecting GGT activity. 
<smiles>O=[N+]([O-])c1ccc(S(=O)(=O)[O-])c([N+](=O)[O-])c1</smiles><smiles>O=[N+]([O-])c1ccc(CS)cc1</smiles>

2, 4-dinitrophenyl glutathione (DNP-GSH) 4-nitrobenzyl (NB-GSH) glutathione

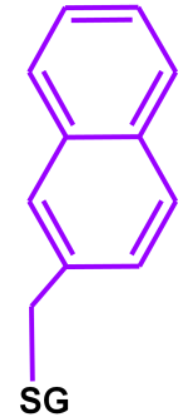

1-menaphthyl glutathione (M-GSH)<smiles>[Se]Cc1c2ccccc2cc2ccccc12</smiles><smiles>[SeH]Cc1ccc(-c2ccccc2)cc1</smiles>

9-methylanthracenyl glutathione (MA-GSH) 4-methylbiphenylyl (MBP-GSH) glutathione

Figure 8. Structures of chemically synthesized GSH conjugates.

SG represents glutathione. 


\section{MATERIALS AND METHODS}

\subsection{MATERIALS}

Bovine serum albumin (BSA; 98\%), 1-(chloromethyl)naphthalene (MCl; menaphthyl chloride; >97\%), GpNA, GSH (>98\%), 2-nitrobenzoic acid (2-NBA; 95\%), 4-nitrobenzyl chloride $(\mathrm{NBCl} ; 99 \%)$, and trichloroacetic acid (TCA) solution $(6.1 \mathrm{~N})$ were obtained from Sigma Aldrich (St. Louis, MO, USA). 4-(Bromomethyl)biphenyl (MBPBr; 96\%) and glygly (99\%) were purchased from Acros Organics (Bridgewater, NJ, USA). 1-Chloro-2,4dinitrobenzene (CDNB; 98\%) and 9-(chloromethyl)anthracene (MACl; 98\%) were obtained from Alfa Aesar (Ward Hill, MD, USA). Bovine kidney GGT was purchased from Lee Biosolutions, Inc. (Brentwood, MO, USA). All other chemicals and reagents were the highest grades commercially available.

\subsection{SYNTHESIS OF GLUTATHIONE CONJUGATES}

GSH conjugates were prepared by a method previously described (Shiotsuki et al., 1990). Previous members of the Josephy laboratory (James Poon and Minah Hwang) assisted with synthesis of GSH conjugates. DNP-GSH was synthesized as follows: CDNB (1 mmol, $203 \mathrm{mg})$ and GSH ( $1 \mathrm{mmol}, 307 \mathrm{mg})$ were added to a solution of $2 \mathrm{M}$ sodium hydroxide $(\mathrm{NaOH} ; 1.0 \mathrm{~mL})$, and $95 \%$ ethanol (EtOH; $1.2 \mathrm{~mL}$ ). The reaction was left to stir overnight at room temperature, and neutralized with concentrated hydrochloric acid $(\mathrm{HCl})$. The precipitate was filtered and thoroughly washed with cold water (to remove any unreacted GSH), EtOH and ethyl acetate (to remove any unreacted $\mathrm{CDNB}$ ). The product was recrystallized from hot 50\% EtOH. The remaining GSH conjugates were synthesized in a similar manner, with the following amounts of $\mathrm{NBCl}$ (172 mg), MCl (177 mg), MACl (227 mg), and MBPBr (247 mg). Reactions containing 
$\mathrm{MACl}$ and $\mathrm{MBPBr}$ were left to stir overnight at $50^{\circ} \mathrm{C}$ in a larger volume of $\mathrm{EtOH}(15-20 \mathrm{~mL})$ to increase yields. Due to low recrystallization yields with MA-GSH and MBP-GSH, washed products were used. Recrystallized, and washed, but not recrystallized GSH conjugates were dissolved in $100 \mathrm{mM}$ Tris- $\mathrm{HCl}(\mathrm{pH}$ 8.0) with stirring at room temperature (DNP-GSH, NB-GSH, M-GSH), or at $37^{\circ} \mathrm{C}$ for $2 \mathrm{~h}$ (MBP-GSH) or overnight (MA-GSH), and used as substrates for enzyme assays.

\subsection{CHARACTERIZATION OF GLUTATHIONE CONJUGATES}

The identities of the GSH conjugates were confirmed by UV-visible spectroscopy, melting points, and electrospray ionization-liquid chromatography-mass spectrometry (ESI-LCMS). GSH conjugates dissolved in $100 \mathrm{mM}$ Tris- $\mathrm{HCl}(\mathrm{pH}$ 8.0) were used for UV-visible spectroscopy analyses (Cary $300 \mathrm{UV}$-visible spectrophotometer); the reference solvent was 100 $\mathrm{mM}$ Tris- $\mathrm{HCl}(\mathrm{pH}$ 8.0). Recrystallized conjugates were used for melting point determinations. GSH conjugates were prepared and sent for ESI-LC-MS as described previously (Poon and Josephy, 2012). Liquid chromatography-mass spectrometry analyses were performed at the Advanced Analysis Centre, University of Guelph, on a Dionex UHPLC UltiMate ${ }^{\circledR} 3000$ liquid chromatograph interfaced to an AmaZon SL ${ }^{\circledR}$ ion trap mass spectrometer (Bruker Daltonics, Billerica, MA, USA). A C18 column (Phenomenex Kinetix ${ }^{\circledR} ; 2.6 \mu \mathrm{m}, 150 \mathrm{~mm} \times 4.6 \mathrm{~mm}$ ) was used for chromatographic separation. The mobile-phase gradient was as follows: initial conditions, $0.1 \%$ formic acid (in water), hold for $5 \mathrm{~min}$; linear gradient to $100 \%$ acetonitrile at $25 \mathrm{~min}$. The flow rate was $0.4 \mathrm{~mL} / \mathrm{min}$. The mass spectrometer electrospray capillary voltage was maintained at $4.5 \mathrm{kV}$ and the drying temperature at $220^{\circ} \mathrm{C}$ with a flow rate of $10 \mathrm{~L} / \mathrm{min}$. Nebulizer pressure was 40 psi. Nitrogen was used as both nebulizing and drying gas; helium was 
used as collision gas at $60 \mathrm{psi}$. The $\mathrm{m} / \mathrm{z}$ was scanned across the range 70-900 in enhanced resolution positive-ion auto MS/MS mode. The Smart Parameter Setting (SPS) was used to automatically optimize the trap drive level for precursor ions. The instrument was externally calibrated with the ESI TuneMix (Agilent).

\subsection{ENZYME ASSAYS}

\subsection{1 $\gamma$-GLUTAMYL- $p$-NITROANILIDE: COLORIMETRIC ASSAY}

Substrates for the standard assay with GGT were prepared based on a previously published protocol (Meister et al., 1981). Donor substrate, GpNA (5 mM; $60 \mathrm{~mL})$ was prepared as follows: GpNA ( $86 \mathrm{mg})$ was dissolved in $1 \mathrm{M} \mathrm{HCl}(20 \mathrm{~mL})$, water $(30 \mathrm{~mL})$ and Tris base $(0.73 \mathrm{~g})$; the solution was brought to $\mathrm{pH} 8$ with $2 \mathrm{M} \mathrm{NaOH}$. Acceptor substrate glygly $(0.1 \mathrm{M}$; $100 \mathrm{~mL})$ was prepared by dissolving glygly $(1.32 \mathrm{~g})$ in water $(80 \mathrm{~mL})$; the solution was brought to $\mathrm{pH} 8.0$ with $2 \mathrm{M} \mathrm{NaOH}$.

The standard assay was performed as previously described (Tate and Meister, 1974; Meister et al., 1981), with the following modifications: incubations (total volume, $1 \mathrm{~mL}$ ) contained GpNA (1 mM), glygly (20 mM), commercial GGT preparation (0.6 $\mu$ g protein), and $100 \mathrm{mM}$ Tris- $\mathrm{HCl}(\mathrm{pH}$ 8.0). Incubations containing no-enzyme were also performed to verify that product formation was enzyme-dependent. Protein concentration was measured by the Bradford assay, with BSA as the standard. The release of $p$-nitroaniline at $37^{\circ} \mathrm{C}$ was monitored for $1 \mathrm{~min}$ at $410 \mathrm{~nm}$ (Cary $300 \mathrm{UV}$-visible spectrophotometer). The specific activity was determined from the rate of $p$-nitroaniline formation $\left(\varepsilon=8800 \mathrm{M}^{-1} \mathrm{~cm}^{-1}\right)$. The standard assay was performed in duplicate. 
For determination of kinetic parameters with GpNA, enzyme assays were performed as described for the standard assay except the concentration of GpNA was varied. Incubations (total volume, $1 \mathrm{~mL})$ contained GpNA (10 $\mu \mathrm{M}-4 \mathrm{mM})$, glygly $(20 \mathrm{mM})$, commercial GGT preparation $(0.6 \mu \mathrm{g}$ protein) and $100 \mathrm{mM}$ Tris- $\mathrm{HCl}(\mathrm{pH}$ 8.0). Control incubations (no enzyme) were also performed. The release of $p$-nitroaniline was monitored at $410 \mathrm{~nm}$ as described above. Initial velocities were determined from the rates of $p$-nitroaniline formation. Four replicate enzyme assays were performed at each concentration of GpNA.

\subsubsection{GLUTATHIONE CONJUGATES: HPLC ASSAY}

Incubations (total volume, $1 \mathrm{~mL}$ ), contained GSH conjugate $(25 \mu \mathrm{M}-1 \mathrm{mM})$, glygly (20 $\mathrm{mM}), \mathrm{GGT}$, and $100 \mathrm{mM}$ Tris- $\mathrm{HCl}(\mathrm{pH} 8.0)$ at $37^{\circ} \mathrm{C}$. The amounts of GGT preparation used were as follows: DNP-GSH, $75 \mu \mathrm{g}$; NB-GSH, $25 \mu \mathrm{g}$; M-GSH, $45 \mu \mathrm{g}$; MA-GSH, $35 \mu \mathrm{g}$; MBP$\mathrm{GSH}, 30 \mu \mathrm{g}$. At specified incubation times ( 0 and $15 \mathrm{sec})$, aliquots $(100 \mu \mathrm{L})$ of the incubation were added to an aliquot of the stop solution $(100 \mu \mathrm{L})$; aqueous TCA (12\%) containing the internal standard, 2-NBA, and vortexed vigorously. The concentrations of 2-NBA internal standard were as follows: DNP-GSH, $1.5 \mathrm{mM}$; NB-GSH and M-GSH, $200 \mu \mathrm{M}$; MA-GSH, 10 $\mathrm{mM}$; MBP-GSH, $100 \mu \mathrm{M}$. After mixing, the stopped solutions were left on ice for $25 \mathrm{~min}$ and then centrifuged for $20 \mathrm{~min}$ at $10,000 \mathrm{x} \mathrm{g}, 4^{\circ} \mathrm{C}$, to sediment protein. The supernatants $(20 \mu \mathrm{L})$ were quantitated by HPLC (see below). No-enzyme controls were performed to verify that substrate (GSH conjugate) depletion and product (Cys-Gly conjugate) formation were enzymedependent. Standard curves were generated based on integrated peak areas; ratio between substrate and internal standard was plotted against substrate concentration. Initial velocities were 
determined from the rate of GSH conjugate depletion. Three replicate enzyme assays were performed at each concentration of GSH conjugate.

HPLC analysis was performed with a Gilson HPLC system comprising an auto-injector (model 234), dual pumps (model 322), UV-visible absorbance detector (model 152), and UniPoint $^{\mathrm{TM}}$ software. The column was a Waters Symmetry® C18 column $(5 \mu \mathrm{m}, 4.6$ x $150 \mathrm{~mm})$. The solvents used were $1 \%$ aqueous acetic acid (solvent A) and acetonitrile (solvent B). The flow rate was $1 \mathrm{~mL} / \mathrm{min}$. UV-visible absorbance was used for detection of the GSH conjugates at the following wavelengths: 4-methylbiphenylyl (MBP), $263 \mathrm{~nm}$; 4-nitrobenzyl (NB), $275 \mathrm{~nm}$ (Tsikas and Brunner, 1992); 1-menaphthylyl (M), 285 nm; 2,4-dinitrophenyl (DNP), $340 \mathrm{~nm}$ (Henderson et al., 1994); 9-methylanthracenyl (MA), $395 \mathrm{~nm}$. HPLC gradients were as follows: DNP-GSH: initial conditions, $10 \%$ B; 0-20 min, hold 10\% B; 20-22 min, gradient to $20 \% \mathrm{~B}$; 2232 min, hold $20 \% \mathrm{~B}$; $32-34 \mathrm{~min}$, gradient to $100 \% \mathrm{~B}$; $34-44 \mathrm{~min}$, hold $100 \% \mathrm{~B}$; $44-46 \mathrm{~min}$, gradient to 10\% B; 46-48 min, hold 10\% B; NB-GSH and M-GSH: initial conditions, 10\% B; 030 min, gradient to $35 \% \mathrm{~B} ; 30-32 \mathrm{~min}$, gradient to $100 \% \mathrm{~B} ; 32-40 \mathrm{~min}$, hold $100 \% \mathrm{~B}$; 40-42 min, gradient to $10 \% \mathrm{~B}$; $42-44$ min, hold 10\% B; MA-GSH: initial conditions, $20 \% \mathrm{~B}$; 0-35 min, gradient to $30 \% \mathrm{~B} ; 35-37 \mathrm{~min}$, gradient to $100 \% \mathrm{~B} ; 37-45$, hold $100 \% \mathrm{~B} ; 45-47$ min, gradient to $20 \% \mathrm{~B}$; 47-49 min, hold 20\% B; MPB-GSH: initial conditions, 20\% B; 0-60 min, gradient to $30 \% \mathrm{~B}$; $60-62$ min, gradient to $100 \% \mathrm{~B} ; 62-70 \mathrm{~min}$, hold $100 \% \mathrm{~B} ; 70-72$ min, gradient to $20 \% \mathrm{~B}$; 72-74 min, hold 20\% B. All gradients were linear.

Michaelis-Menten kinetic parameters $K_{m}$ and $\mathrm{V}_{\max }$ were determined by non-linear curve fitting with SigmaPlot software (Systat Software, Inc., Chicago, IL, USA). For each substrate, the data sheet consisted of a separate row ( $\mathrm{S}, \mathrm{v}_{0}$ pair) for each determination, and the Michaelis- 
Menten curve was fit to the entire data set. Thus, the error estimates made by the software reflect both the experimental variability and the goodness -of- fit. 


\section{RESULTS}

\subsection{CHARACTERIZATION OF GLUTATHIONE CONJUGATES}

GSH conjugates were synthesized as described in section 3.2. Recrystallized (DNP-GSH, NB-GSH, M-GSH) and washed, but not recrystallized (MA-GSH and MBP-GSH) conjugates were weighed and dissolved in $100 \mathrm{mM}$ Tris-HCl buffer ( $\mathrm{pH} 8.0)$, and were used as substrates for enzyme assays.

Analytical data confirming the identities of the GSH conjugates are presented in Table 3. Single determinations were performed for yield, UV-visible spectrometry, melting points, and mass-to-charge ratio analyses. GSH conjugates dissolved in $100 \mathrm{mM}$ Tris- $\mathrm{HCl}(\mathrm{pH} 8.0)$ buffer were used for UV-visible spectrometry; crude products were used to determine yield; recrystallized conjugates were used for melting point analysis. ESI-LC-MS analysis was performed as described previously (Poon and Josephy, 2012); the mass spectra of the GSH conjugates are found in Appendix A.

Crude yields $(\%)$ of $60,50,30,25$, and 15 were observed for NB-GSH, DNP-GSH, MGSH, MA-GSH and MBP-GSH. It appears that as the polarity of the electrophile decreases, the product yield is lower. A likely explanation is that the more non-polar GSH conjugates (M-GSH, MA-GSH and MBP-GSH) are less soluble in polar solvents (water, EtOH). The addition of heat and increasing the volume of the reaction solvent $(\mathrm{EtOH})$ were necessary to obtain higher yields for the polycyclic conjugates, MA-GSH and MBP-GSH.

UV absorbance peak wavelengths were determined for all GSH conjugates. The observed values obtained for DNP-GSH $(340 \mathrm{~nm})$ and NB-GSH $(275 \mathrm{~nm})$ were similar to reported literature values of $340 \mathrm{~nm}$ and $270 \mathrm{~nm}$, for DNP-GSH and NB-GSH, respectively (Tsikas and Brunner, 1992; Henderson et al., 1994). Values observed for the other conjugates were $285 \mathrm{~nm}$ 
Table 3. Properties of GSH conjugates.

GSH conjugates dissolved in $100 \mathrm{mM}$ Tris- $\mathrm{HCl}(\mathrm{pH} 8.0)$ were analyzed by UV-visible spectroscopy. Recrystallized GSH conjugates were used for melting point determinations. ESILC-MS analysis was performed as described previously (Poon and Josephy, 2012). Single point determinations were performed for yields, UV absorbance peak wavelengths, melting points and mass-to charge ratios.

\begin{tabular}{|c|c|c|c|c|c|c|c|}
\hline \multirow[t]{2}{*}{ Substrate } & \multirow{2}{*}{$\begin{array}{l}\text { Yield } \\
(\%)\end{array}$} & \multicolumn{2}{|c|}{$\lambda_{\max }(\mathbf{n m})$} & \multicolumn{2}{|c|}{ m.p. $\left({ }^{\circ} \mathbf{C}\right)$} & \multicolumn{2}{|c|}{ mass spec. } \\
\hline & & obs. & lit. & obs. & lit. & calc. & $\begin{array}{l}\text { obs. } \\
(\mathbf{M}+\mathbf{H})^{+}\end{array}$ \\
\hline DNP-GSH & 50 & 340 & $340^{3}$ & 195 & $\begin{array}{l}190- \\
194^{1}\end{array}$ & 473.1 & 474.1 \\
\hline NB-GSH & 60 & 275 & $270^{2}$ & 200 & - & 442.1 & 443.1 \\
\hline M-GSH & 30 & 285 & - & 203 & $210^{4}$ & 447.2 & 448.1 \\
\hline MA-GSH & 25 & 395 & - & N.D & - & 497.2 & 498.1 \\
\hline MBP-GSH & 15 & 263 & - & N.D & - & 473.2 & 474.1 \\
\hline
\end{tabular}

Obs., observed; lit., literature; m.p., melting point; calc., calculated; N.D., not determined.

References: Hinchman et al., 1991 ${ }^{1}$; Tsikas and Brunner, $1992^{2}$; Henderson et al., $1994^{3}$; Hyde and Young, $1968^{4}$ 
(M-GSH), $395 \mathrm{~nm}$ (MA-GSH) and $263 \mathrm{~nm}$ (MBP-GSH).

Melting points were determined for the recrystallized GSH conjugates: DNP-GSH, NBGSH and M-GSH. Reported literature values for DNP-GSH $\left(190-194^{\circ} \mathrm{C}\right)$ and M-GSH $\left(210^{\circ} \mathrm{C}\right)$ were similar to the observed values of $195^{\circ} \mathrm{C}$ and $210^{\circ} \mathrm{C}$, for DNP-GSH and M-GSH, respectively (Hyde and Young, 1968; Hinchman et al., 1991). For NB-GSH, the melting point was $200^{\circ} \mathrm{C}$.

\subsection{SDS-PAGE ANALYSIS OF $\gamma$-GLUTAMYLTRANSFERASE}

Commercial bovine kidney GGT preparation was analyzed by SDS-PAGE to confirm its identity. The Coomassie-stained gel is shown in Figure 9. Many bands were present, which was expected, because the manufacturers did not claim that the GGT preparation was purified to homogeneity.

\subsection{ENZYME ASSAYS}

\subsection{1 $\gamma$-GLUTAMYL- $p$-NITROANILIDE: COLORIMETRIC ASSAY}

To confirm the activity of the commercial GGT preparation, the standard assay for GGT activity was performed, as described in section 3.4.1. GGT cleaves the $\gamma$-glutamyl bond of GpNA, releasing $p$-nitroaniline, which is detected at $410 \mathrm{~nm}$. The measured specific activity was $30 \pm 2.01 \mu \mathrm{mol} / \mathrm{min} / \mathrm{mg}$; the specification from Lee Biosolutions was $38 \mu \mathrm{mol} / \mathrm{min} / \mathrm{mg}$. Therefore, the measured activity was similar to the value stated by the manufacturers.

To determine Michaelis-Menten parameters, the activity was measured as a function of GpNA concentration (Figure 10); kinetic parameters are given in Table 4. The measured $K_{m}$ for bovine kidney GGT was $0.74 \mathrm{mM} ; \mathrm{V}_{\max }, 39 \mu \mathrm{mol} / \mathrm{min} / \mathrm{mg} ; \mathrm{V}_{\max } / \mathrm{K}_{\mathrm{m}}$ (catalytic efficiency), 


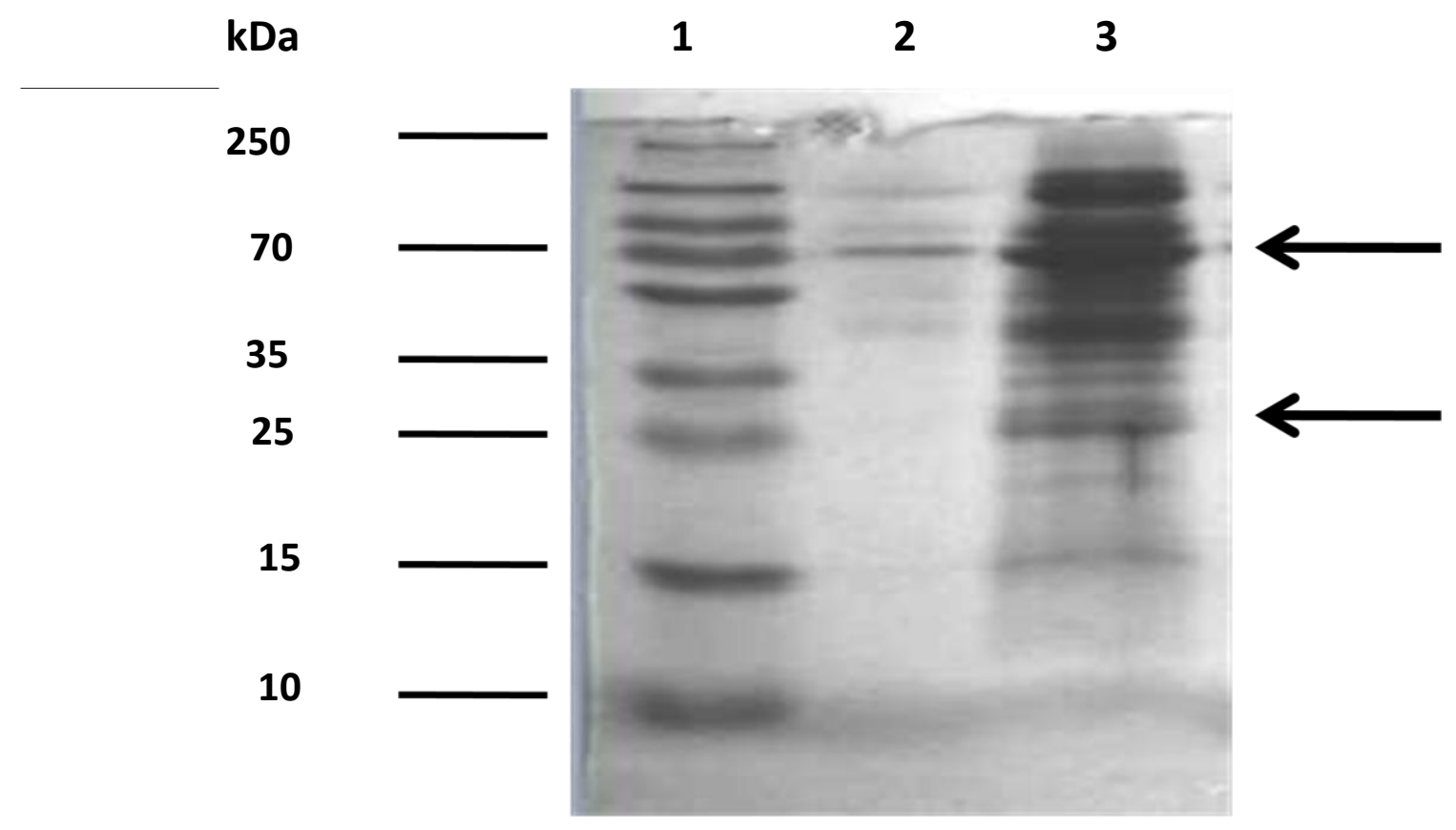

Figure 9. Coomassie-stained SDS-PAGE gel of GGT preparation.

Lane 1: MW standard PageRuler ${ }^{\mathrm{TM}}$ Plus; lane 2 minor spill-over from lane 3; lane 3: commercial bovine kidney GGT preparation (12 $\mu \mathrm{g}$ protein) from Lee Biosolutions, Inc. Arrows indicate the anticipated positions of the heavy and light chains, approximately 70 and $25 \mathrm{kDa}$, respectively (Tate et al., 1988). 


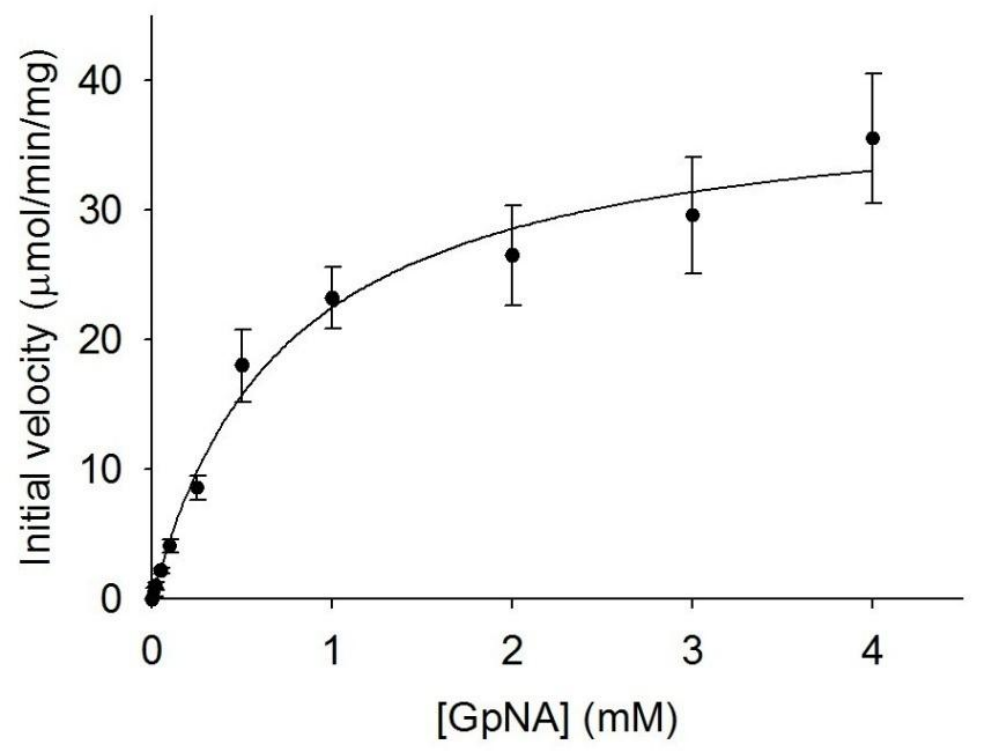

Figure 10. Hydrolysis of GpNA catalyzed by GGT.

GpNA assay was performed as described in section 3.4.1. Initial velocities were determined from rates of $p$-nitroaniline formation. Data points represent mean initial velocities of four replicates. Error bars represent standard deviations of the initial velocities. Data were fit by non-linear curve fitting (SigmaPlot software). 
Table 4. Kinetics of GGT-catalyzed hydrolysis of GpNA.

$\mathrm{K}_{\mathrm{m}}, \mathrm{V}_{\max }$, and standard errors were calculated from non-linear regression of the MichaelisMenten equation, as described in Materials and Methods.

\begin{tabular}{|l|l|l|l|}
\hline Substrate & $K_{\mathrm{m}}(\mathrm{mM})$ & $\begin{array}{l}\mathrm{V}_{\max } \\
(\mu \mathrm{mol} / \mathrm{min} / \mathrm{mg})\end{array}$ & $\begin{array}{l}\mathrm{V}_{\max } / \mathrm{K}_{\mathrm{m}} \\
(\mathrm{mL} / \mathrm{min} / \mathrm{mg})\end{array}$ \\
\hline GpNA & $\mathbf{0 . 7 4} \pm \mathbf{0 . 1 2}$ & $39 \pm 1.99$ & $53 \pm 9.01$ \\
\hline
\end{tabular}


$53 \mathrm{~mL} / \mathrm{min} / \mathrm{mg}$.

\subsubsection{GLUTATHIONE CONJUGATES: HPLC ASSAY}

Preliminary studies were performed to verify the linearity of the enzyme assays with GSH conjugates. The enzyme assays were separated and quantitated by HPLC as described in section 3.4.2. The progress of the reaction was monitored by measuring the disappearance of the donor substrate (GSH conjugate). Figure 11 is a representative progress curve depicting linearity of the enzyme assays with GSH-conjugates; DNP-GSH was the substrate. Linearity was achieved from 0-30 sec with all GSH conjugates; however, assays were performed from 0-15 sec with three replicates. Substrate depletion of $20-25 \%$ was observed for each GSH conjugate from 0-15 sec, with the amounts of commercial GGT preparation stated in section 3.4.2. Progress curves for the remaining GSH conjugates are found in Appendix B.

Figure 12 depicts representative chromatograms of the enzyme incubations. Peaks correspond to 2-NBA (internal standard), M-Cys-Gly (M-CG), M-Cys (M-C) (products), and MGSH (donor substrate). The identities of these peaks were verified through HPLC analysis and comparison with standards. The small amounts of product formation observed at $0 \mathrm{sec}$ (Figure 12A) are negligible because the GSH conjugate initial substrate concentration was verified through the standard curve. In addition, the initial substrate concentration of the GSH conjugate from a no enzyme control was verified through the standard curve. These initial substrate concentrations from incubations with and without enzyme were very similar. Standard curves are

found in Appendix C. GSH conjugate depletion and Cys-Gly conjugate formation were observed over time (Figure 12B). Neither substrate depletion nor product formation was observed during HPLC analysis of the no-enzyme controls, which confirmed that the reaction is enzyme- 


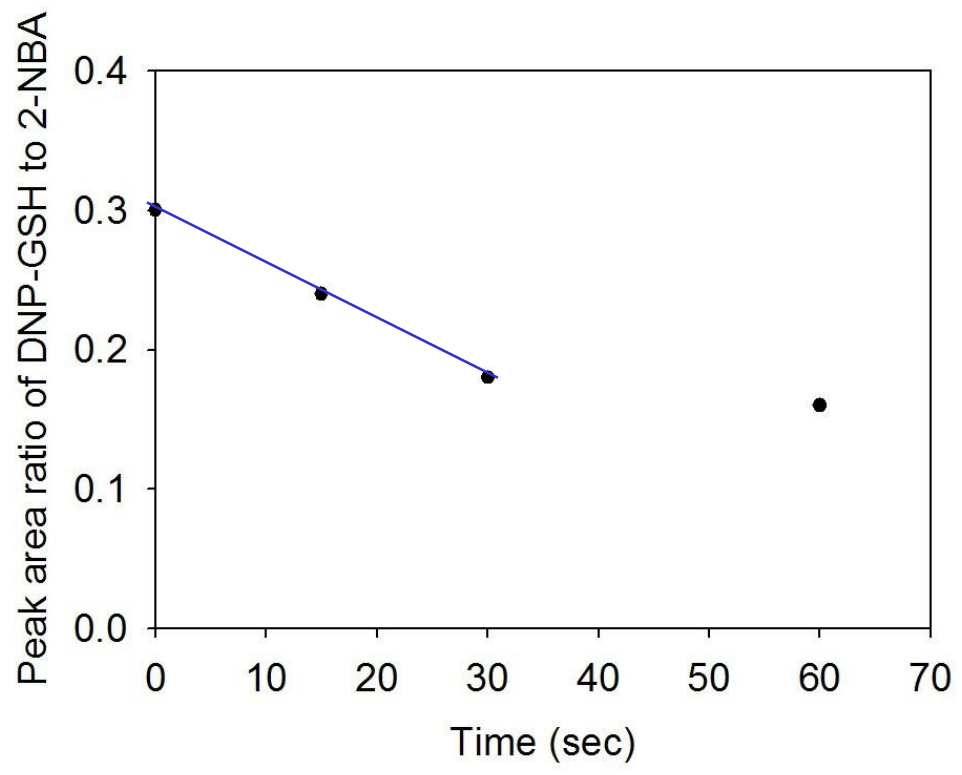

Figure 11. Representative progress curve depicting linearity of enzyme assay with GSH conjugates.

DNP-GSH was the donor substrate. Incubations $(1 \mathrm{~mL})$ performed at $37^{\circ} \mathrm{C}$, contained DNP-GSH $(100 \mu \mathrm{M})$, glygly $(20 \mathrm{mM})$, commercial GGT preparation $(75 \mu \mathrm{g}$ protein) and $100 \mathrm{mM}$ Tris- $\mathrm{HCl}$ $(\mathrm{pH} 8.0)$. Aliquots $(100 \mu \mathrm{L})$ of the reaction were added to the stop solution (12\% TCA and 1.5 $\mathrm{mM} 2-\mathrm{NBA})$, at $0,15,30$ and $60 \mathrm{sec}$. Supernatants $(20 \mu \mathrm{L})$ were quantitated by HPLC. The assay was performed as a single replicate. 


\section{A) 0 sec}

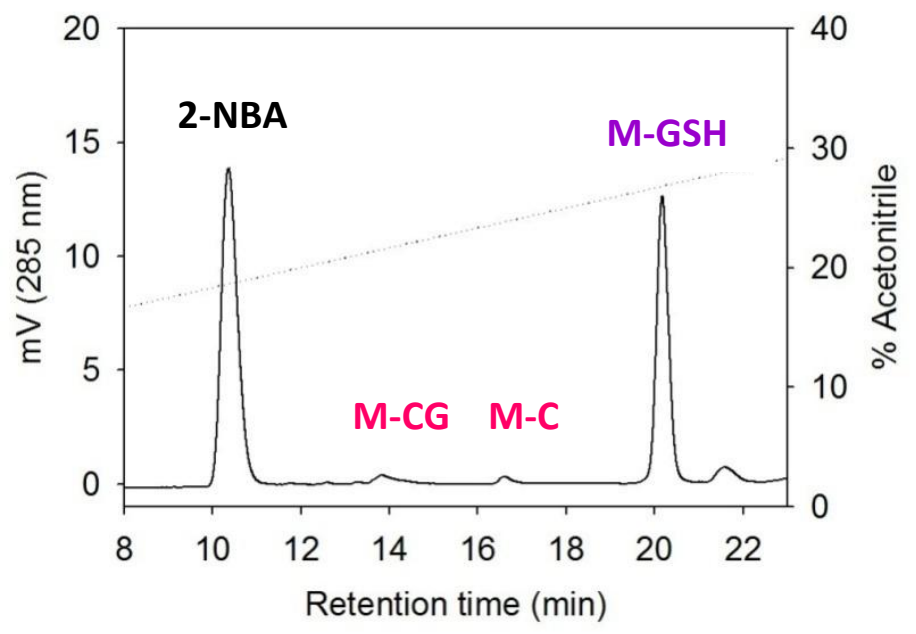

B) $15 \mathrm{sec}$

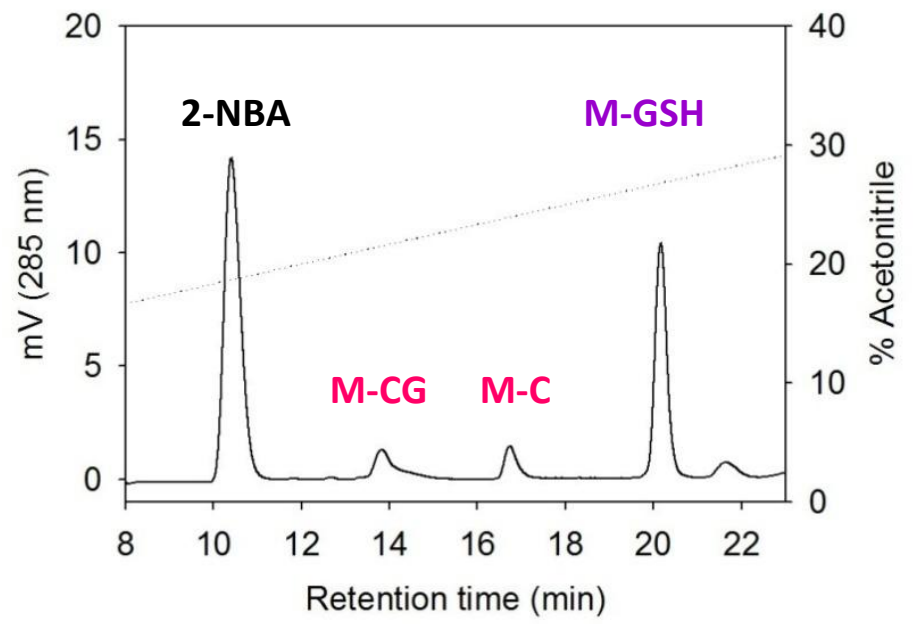

Figure 12. Representative chromatograms of the HPLC separation of enzyme assay at 0 sec (A) and $15 \sec (B)$.

Donor substrate was M-GSH. Incubations $(1 \mathrm{~mL})$ performed at $37^{\circ} \mathrm{C}$, contained M-GSH (400 $\mu \mathrm{M})$, glygly $(20 \mathrm{mM})$, commercial GGT preparation (45 $\mu \mathrm{g}$ protein) and $100 \mathrm{mM}$ Tris- $\mathrm{HCl}(\mathrm{pH}$ 8.0). Aliquots $(100 \mu \mathrm{L})$ of the reaction were added to the stop solution (12\% TCA and $200 \mu \mathrm{M} 2$ NBA), at 0 and $15 \mathrm{sec}$. Supernatants $(20 \mu \mathrm{L})$ were quantitated by HPLC. 
dependent (data not shown). The Cys-Gly conjugates did not accumulate in proportion to the disappearance of the GSH conjugate, presumably because of further hydrolysis to give the Cys conjugates. Similar amounts of Cys-Gly and Cys conjugates were observed. To test this possibility, the Cys-Gly conjugates were incubated with the GGT enzyme preparation and formation of the Cys conjugates, verified by co-elution with synthetic Cys conjugate standards, was observed (data not shown). In addition, incubations of the Cys-Gly conjugates without GGT enzyme preparation were performed, and no Cys conjugate formation was observed (data not shown). This may indicate the presence of some extraneous dipeptidase enzyme activity in the GGT preparation, but should not affect the initial rates measured from the progress curves. As a result, GSH conjugate depletion was monitored because Cys-Gly conjugate formation could not be accurately quantitated, due to further hydrolysis to the Cys conjugate.

Chromatograms depicting the enzymatic hydrolysis (at $15 \mathrm{sec}$ ) of the remaining GSH conjugates are found in Appendix D. Cys-Gly and Cys conjugates of DNP, NB, MA, and MBP were also observed. Similar amounts of the Cys-Gly and Cys conjugates were noted. HPLC analysis of the enzyme incubation with MBP-GSH indicated co-elution of the Cys-Gly product and buffer components; therefore, a blank control (enzyme; no substrate) was also analyzed and subtracted from the enzyme incubation to measure Cys-Gly formation. Additional controls (no enzyme, or substrate) for the blank were performed to verify that formation of the peak was due to Cys-Gly formation, when enzyme and substrate are both present (data not shown). Lower resolution of the chromatogram of MA-GSH hydrolysis was observed, probably due to reaching the lower detection limit of the UV-visible absorbance detector.

The hydrolysis of the GSH conjugates by commercial bovine kidney GGT is shown in Figure 13; kinetic parameters are depicted in Table 5. GpNA had the highest $K_{m}(0.74 \mathrm{mM})$ 

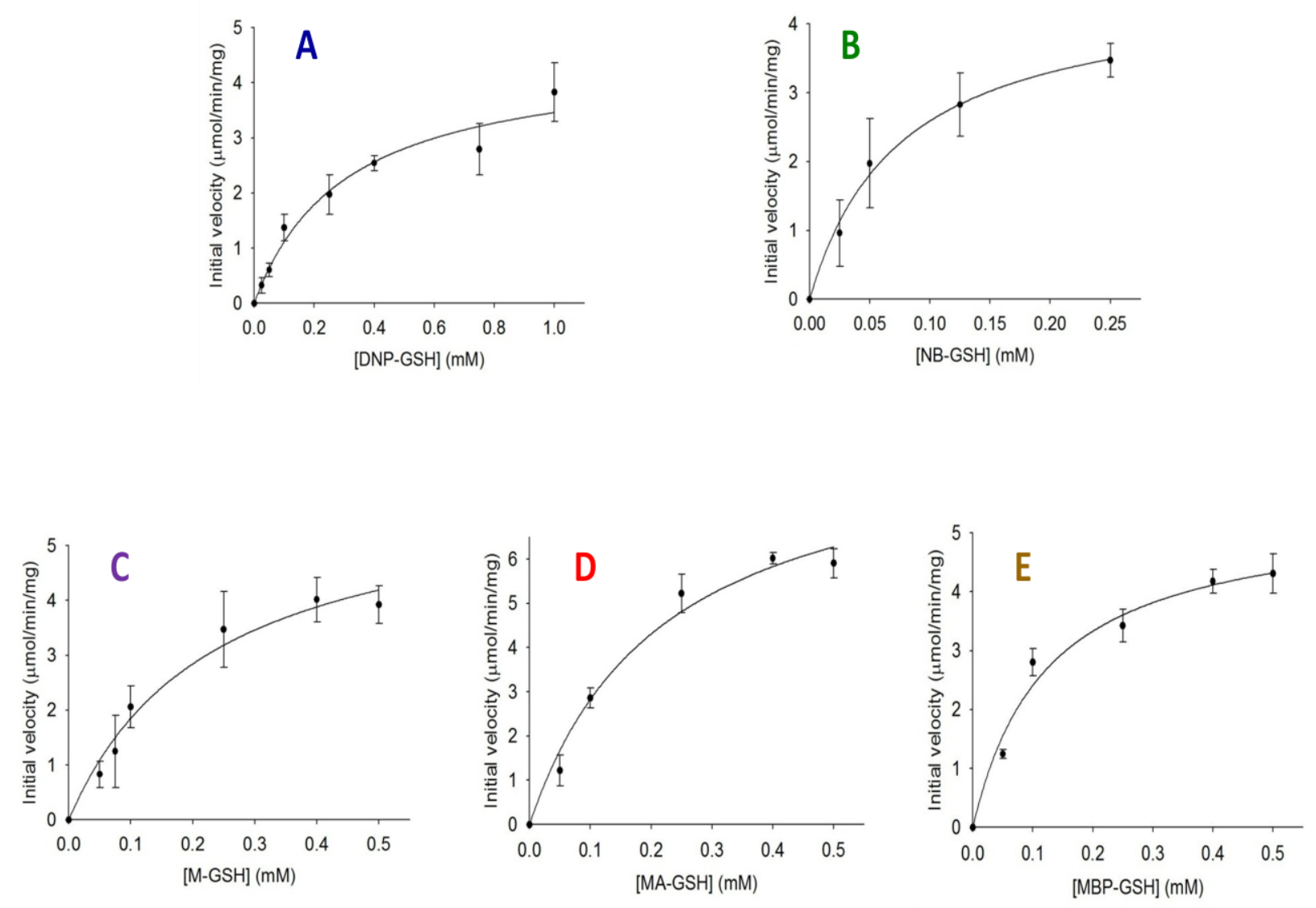

Figure 13. Hydrolysis of substrates catalyzed by GGT: DNP-GSH (A); NB-GSH (B); M-GSH (C); MA-GSH (D); MBP-GSH (E).

GSH conjugates were quantitated by HPLC. Initial velocities were determined from GSH conjugate depletion through peak area integrated standard curves. Data points represent mean initial velocities of three replicates. Error bars represent standard deviations of the initial velocities. Data were fit by non-linear curve fitting (SigmaPlot software). 
Table 5. Kinetics of GGT-catalyzed hydrolysis of GSH conjugates.

$\mathrm{K}_{\mathrm{m}}, \mathrm{V}_{\max }$, and standard errors were calculated from non-linear regression of the MichaelisMenten equation, as described in Materials and Methods.

\begin{tabular}{|l|l|l|l|}
\hline Substrate & $\mathrm{K}_{\mathrm{m}}(\mathrm{mM})$ & $\begin{array}{l}\mathrm{V}_{\max } \\
(\mu \mathrm{mol} / \mathrm{min} / \mathrm{mg})\end{array}$ & $\begin{array}{l}\mathrm{V}_{\max } / \mathrm{K}_{\mathrm{m}} \\
(\mathrm{mL} / \mathrm{min} / \mathrm{mg})\end{array}$ \\
\hline GpNA & $0.74 \pm 0.12$ & $39.12 \pm 1.99$ & $53.01 \pm 9.01$ \\
\hline DNP-GSH & $0.30 \pm 0.09$ & $4.50 \pm 0.50$ & $14.85 \pm 4.80$ \\
\hline NB-GSH & $0.08 \pm 0.01$ & $4.53 \pm 0.31$ & $60.56 \pm 9.66$ \\
\hline M-GSH & $0.23 \pm 0.06$ & $6.11 \pm 0.72$ & $26.57 \pm 7.73$ \\
\hline MA-GSH & $\mathbf{0 . 2 2} \pm 0.06$ & $9.01+1.07$ & $41.35 \pm 12.2$ \\
\hline MBP-GSH & $0.12 \pm 0.03$ & $5.38 \pm 0.46$ & $43.86 \pm 11.6$ \\
\hline
\end{tabular}


and $\mathrm{V}_{\max }(39 \mu \mathrm{mol} / \mathrm{min} / \mathrm{mg})$; NB-GSH had the lowest $K_{m}(0.075 \mathrm{mM})$. 


\section{DISCUSSION}

The objective of this study was to examine the effects of aromatic substituents attached to the sulfur atom of GSH conjugates (as donor substrates) on the activity of mammalian GGT, as a contribution to understanding the role of GSH-dependent metabolism in the toxicology of aromatic and polycyclic aromatic xenobiotics. To provide a basis for comparison with literature values, we also included GpNA, the standard chromogenic substrate for GGT. $K_{m}$ values for GpNA have been reported as $0.8 \mathrm{mM}$ (bovine liver; (Furukawa et al., 1983)), $0.9 \mathrm{mM}$ (rat pancreas; (Takahashi et al., 1982)), and $0.6 \mathrm{mM}$ (recombinant human enzyme; (Castonguay et al., 2007)), similar to our determination of $0.74 \pm 0.1 \mathrm{mM}$. Furthermore, Wickham and colleagues performed an enzyme kinetic analysis with NB-GSH and obtained a value $K_{m}=13$ $\mu \mathrm{M}$ for recombinant human GGT1, compared to our determination of $75 \mu \mathrm{M}$. However, the assay conditions (hydrolytic mode without an acceptor substrate; coupled colorimetric assay for glutamate release) were very different from those used in our study (Wickham et al., 2011).

The results indicated that the S-substituent of GSH affects enzyme activity, but not strongly. Examination of the donor substrate specificity of rat kidney GGT with small $\gamma$-glutamyl compounds by Cook and colleagues suggested that donor substrate structure is not fundamental in determining the selectivity of the enzyme. "Thus, ring structures, long-chained and branchedchain", hydrophobic or charged structures, "were tolerated by the enzyme" (Cook et al., 1987). In addition, crystal structures of bacterial GGTs, and studies of conserved active site residues of human GGT, indicate that the $\gamma$-glutamyl moiety is the primary determinant recognized; the CysGly moiety is believed to be solvent-exposed (Ikeda et al. 1993, 1995; Okada et al. 2006; Morrow et al. 2007). 
Even though the $\gamma$-glutamyl moiety of the donor substrate is critical to substrate recognition by GGT, the role of the S-substituent should not be ignored. Mammalian and bacterial GGTs contain a donor substrate binding loop that undergoes conformational changes to allow substrate entry into the active site (Okada et al. 2006; Morrow et al. 2007; Hu et al. 2012). The conserved aromatic gating residue (Tyr in H. pylori and E. coli GGT; Phe in human GGT) of the donor substrate binding loop might be involved in stacking interactions with the aromatic S-substituent of the GSH conjugates, leading to slightly lower $K_{m}$ values of GGT for the GSH conjugates. Figure 14 depicts the donor substrate binding site of $H$. pylori GGT, and the conserved active site residues involved in recognition of the bound substrate, NB-GSH.

Additional structure-dependent trends can be suggested to explain the lower $K_{m}$ values of GGT for the GSH conjugates. DNP-GSH has the cysteine S atom bonded directly to the aromatic ring; the remaining four GSH conjugates are benzylic adducts, with the cysteine $\mathrm{S}$ atom connected to an aromatic ring via a methylene bridge (Figure 8). If the aromatic system of the donor substrate is excluded from the active site, it may place a restriction of the $\gamma$-glutamyl moiety entering the active site, and this would be greatest for DNP-GSH, where the distance between the aryl ring and the $\gamma$-glutamyl group is shortest. This explanation is consistent with the higher value of $K_{m}$ for DNP-GSH. Among the remaining four benzylic adducts, there is a consistent, albeit slight, trend towards higher $K_{m}$ values for bulkier substrates, with the lowest values seen for NB-GSH (single ring) and MBP-GSH (biphenyl), and higher values for the fused bicyclic (M-GSH) and tricyclic (MA-GSH) substrates. If this trend is substantiated, it would 


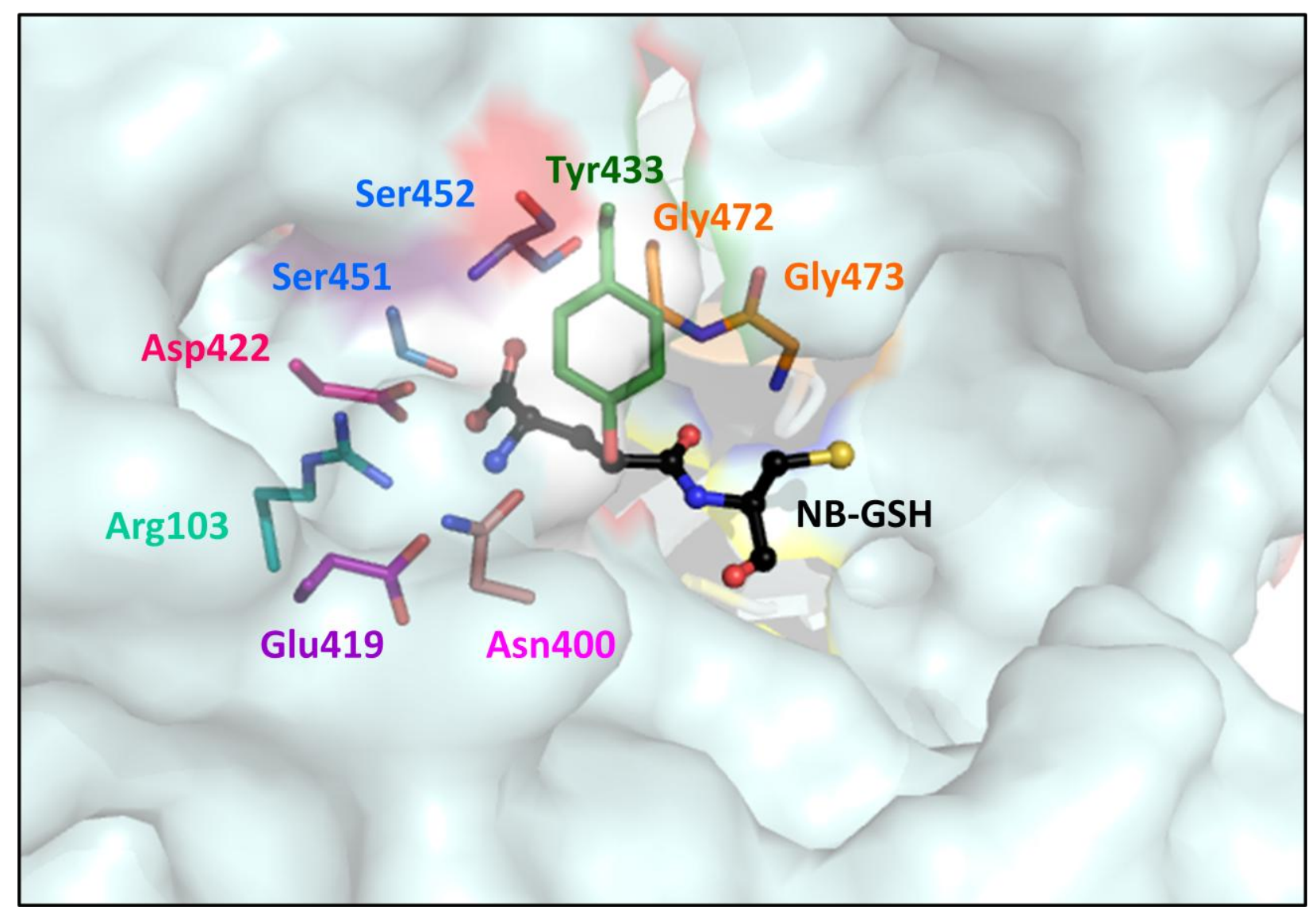

Figure 14. Donor substrate binding site of $\boldsymbol{H}$. pylori GGT.

PDB file 2QMC. Side chains of conserved active site residues and gating residue are shown as coloured sticks; bound NB-GSH (black) is shown in ball-and-stick representation. Oxygen, nitrogen and sulfur atoms are depicted in red, blue and yellow, respectively. The $\gamma$-glutamyl moiety of the donor substrate is buried in the core of the enzyme and is recognized by the conserved active site residues. The S-substituent may participate in stacking interactions with the gating residue, Tyr433. Figure was generated with PyMOL (The PyMOL Molecular Graphics System, Version 1.3, Schrödinger, LLC). 
imply that larger polycyclic structures, such as benzo[ $a]$ pyrene adducts, may have even higher $K_{m}$ values.

Molecular dynamics simulations of human GGT indicate that the Cys-Gly moiety points towards, or possibly overlaps, with the acceptor substrate binding site (Hu et al., 2012). It is feasible that the Cys-Gly moiety could participate in interactions with residues near or within the acceptor substrate binding site; Lys562 and Tyr403 of the human GGT were observed in electrostatic interactions, and hydrogen bonds, respectively, with the glycyl carboxylate moiety of GSH (Hu et al., 2012). The small increase in affinity of GGT for the GSH conjugates could be the result of these interactions further stabilizing the GSH conjugates.

In contrast, $\mathrm{V}_{\max }$ values for all five GSH conjugates are very similar. This is consistent with the expectation that S-substituents, being far from the scissile $\gamma$-glutamyl isopeptide bond, have little effect on the progress of the reaction under conditions where the enzyme is saturated with substrate.

GGT had the highest $K_{m}$ with GpNA. It is possible that the nitroaniline group, attached directly to the $\gamma$-glutamyl moiety, might also restrict substrate entry into the active site. In addition, GpNA does not contain a Cys-Gly moiety, so the interactions that were proposed to stabilize the glycyl moiety of GSH (Hu et al., 2012) could explain why GpNA had a slightly higher $K_{m}$. On the other hand, $\mathrm{V}_{\max }$ was the highest with GpNA, because the nitroaniline group is more electron-withdrawing, causing a faster rate of hydrolysis (Cook et al., 1987).

The catalytic efficiencies $\left(\mathrm{V}_{\max } / \mathrm{K}_{\mathrm{m}}\right)$ varied by only about a factor of 4 among the aromatic substituents, which varied in size from a single ring (2,4-dinitrophenyl and 4nitrobenzyl) to three rings (9-methylanthracenyl). These findings suggest that even larger 
aromatic substituents, such as five-ring benzo[a]pyrene derivatives, may also be accommodated by mammalian GGT.

To date, this is the first systematic study of the effects of aromatic S-substituents that has been reported (Agblor and Josephy, submitted). These results agree with literature on GGT which states that the gamma-glutamyl moiety is the primary determinant recognized by the enzyme. However; we have further elucidated the possible effects of the aromatic S-substituents on enzymatic activity. In addition, this is the first representative study on the xenobiotic donor substrate specificity of bovine kidney GGT. 


\section{CONCLUSIONS}

The specificity of GGT for xenobiotic donor substrates, to date, is poorly understood. The aim of this study was characterize the donor substrate specificity of GGT, and further elucidate the structural factors affecting enzyme activity. We prepared several GSH conjugates representative of detoxication products of aromatic xenobiotics, and confirmed their identities. We developed HPLC methods for separation and quantitation. The chromogenic substrate, GpNA was also tested with the standard assay used to measure GGT activity. It was concluded that even though the S-substituent attached to GSH affects enzyme activity, but not strongly, a slight trend was observed consistent with a relationship between $K_{m}$ value and bulky Ssubstituents.

Future directions of this study might involve examination of the donor substrate specificity of human GGT; this research has laid the foundation for studies with human GGT. King and colleagues identified a novel uncompetitive inhibitor, OU749 (N-[5-(4methoxybenzyl)-1,3,4-thiadiazol-2-yl]-benzenesulfonamide), that exhibited specificity between mammalian GGTs. Recombinant human GGT expressed in $P$. pastoris displayed $65 \%$ inhibition, whereas pig, rat and mouse, and monkey GGT displayed 10\%, 20\% and 25\% inhibition, respectively. Even though there is a high degree of conservation between mammalian GGTs (Figure 15) there could be structural differences that could lead to donor substrate specificity differences between mammalian GGTs. In fact, $\mathrm{Hu}$ and colleagues proposed that differences in inhibition could be due to differences in the acceptor substrate site residues between mammalian GGTs (Hu et al., 2012). It was suggested that OU749 binds in a hydrophobic pocket within the acceptor substrate binding site, and certain residues involved in hydrogen bonding could prevent OU749 from binding within the pocket. Modeled studies of human GGT with OU749 indicate 

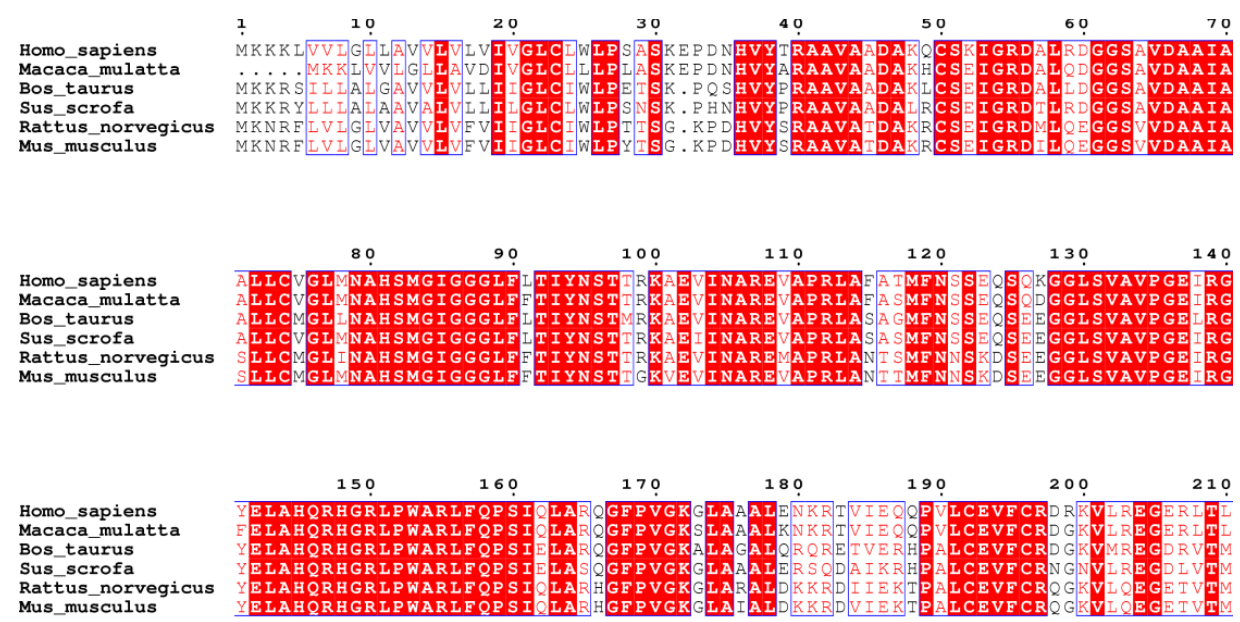

GFPVGK
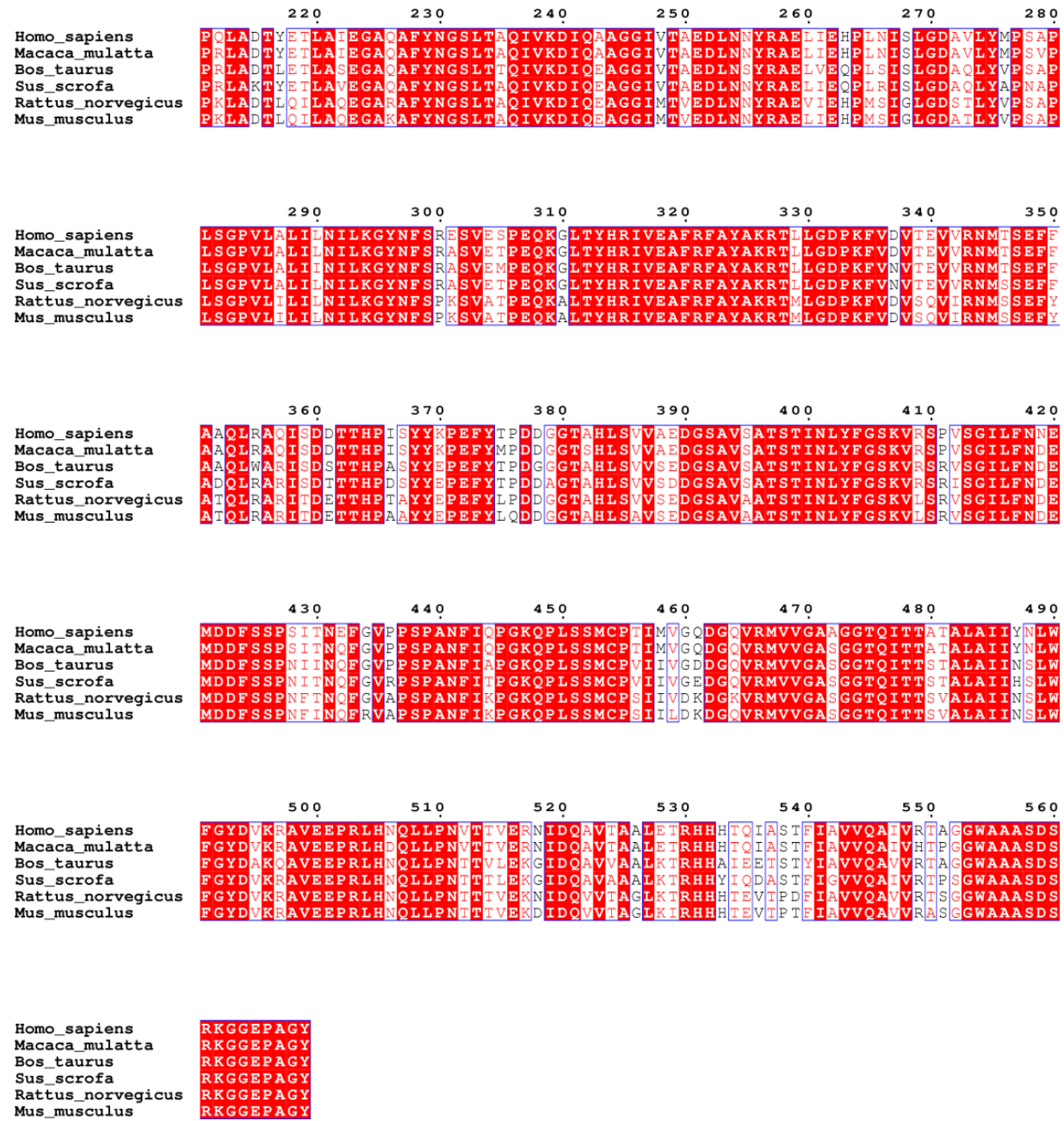

Figure 15. Multiple sequence alignment of mammalian GGT. Red boxes represent sequence identity between human, bovine, rat, mouse, pig and monkey GGT. 
that because human GGT has Ala472, it is probably not participating in a hydrogen bond with Lys562. In contrast, rat, mouse and pig GGT have a Ser at position 472 that can hydrogen bond to Lys562, resulting in a "closed conformation of the hydrophobic binding pocket of the acceptor substrate binding site" preventing OU749 from binding, illustrating the differences in inhibition (Hu et al., 2012). Therefore, it might be worthwhile to investigate the donor substrate specificity of human GGT with the substrates used in this study.

Furthermore, human genomic analysis has identified multiple members of the human GGT family, 6 of the 13 members may be functional proteins (Heisterkamp et al., 2008). Since few have been enzymatically characterized, it would beneficial to study the donor substrate specificity of human GGTs.

In addition, it would be interesting to perform binding experiments with tryptophan fluorescence spectroscopy, and determine whether there is any correlation between binding $\left(K_{d}\right)$ and affinity $\left(K_{m}\right)$. Increasing amounts of donor substrate would be added to the enzyme incubation, which would cause a shift in the emission spectrum of the Trp residues intrinsic to GGT, indicating a conformational change of the protein as substrate binds to the active site.

This research has provided insight into the donor substrate specificity of bovine kidney GGT, and has further established the importance of GGT in the elimination of polycyclic aromatic xenobiotics through the mercapturic acid pathway. 


\section{REFERENCES}

Agblor AA, Josephy PD. (2012). Donor substrate specificity of gamma-glutamyltransferase. Submitted.

Angeli V, Tacito A, Paolicchi A, Barsacchi R, Franzini M, Baldassini R, Vecoli C, Pompella A, Bramanti E. (2009). A kinetic study of gamma-glutamyltransferase (GGT)-mediated Snitrosoglutathione catabolism. Arch Biochem Biophys 481:191-196.

Arai K, Yoshida K, Komoda T, Sakagishi Y. (1990). Comparative studies on the properties of purified gamma-glutamyl transferase from human reproductive system and the kidney. Clin Biochem 23:105-112.

Binkley F, Nakamura K. (1948). Metabolism of glutathione; hydrolysis by tissues of the rat. J Biol Chem 173:411-421.

Carter BZ, Wiseman AL, Orkiszewski R, Ballard KD, Ou CN, Lieberman MW. (1997). Metabolism of leukotriene C4 in gamma-glutamyl transpeptidase-deficient mice. J Biol Chem 272:12305-12310.

Castonguay R, Halim D, Morin M, Furtos A, Lherbet C, Bonneil E, Thibault P, Keillor JW. (2007). Kinetic characterization and identification of the acylation and glycosylation sites of recombinant human gamma-glutamyltranspeptidase. Biochemistry 46:12253-12262.

Castonguay R, Lherbet C, Keillor JW. (2003). Kinetic studies of rat kidney gammaglutamyltranspeptidase deacylation reveal a general base-catalyzed mechanism. Biochemistry 42:11504-11513.

Commandeur JN, Stijntjes GJ, Vermeulen NP. (1995). Enzymes and transport systems involved in the formation and disposition of glutathione S-conjugates. Role in bioactivation and detoxication mechanisms of xenobiotics. Pharmacol Rev 47:271-330.

Cook ND, Upperton KP, Challis BC, Peters TJ. (1987). The donor specificity and kinetics of the hydrolysis reaction of gamma-glutamyltransferase. Biochim Biophys Acta 914:240-245.

Das ND, Shichi H. (1979). Gamma-Glutamyl transpeptidase of bovine ciliary body: purification and properties. Exp Eye Res 29:109-121.

Del Corso A, Cappiello M, Buono F, Moschini R, Paolicchi A, Mura U. (2006). Colorimetric coupled enzyme assay for gamma-glutamyltransferase activity using glutathione as substrate. $\mathrm{J}$ Biochem Bioph Methods 67:123-130.

Ding JL, Smith GD, Peters TJ. (1980). The purification of gamma-glutamyltransferase from normal rat liver. Biochem Soc Trans 8:77.

Ding JL, Smith GD, Peters TJ. (1981). Purification and properties of gamma-glutamyl transferase from normal rat liver. Biochim Biophys Acta 657:334-343. 
Furukawa M, Higashi T, Tateishi N, Ochi K, Sakamoto Y. (1983). Purification and properties of bovine liver gamma-glutamyltransferase. J Biochem 93:839-846.

Gonzalez FJ. (1988). The molecular biology of cytochrome P450s. Pharmacol Rev 40:243-288.

Grant DM. (1991). Detoxification pathways in the liver. J Inherit Metab Dis 14:421-430.

Hanes CS, Hird FJ. (1950). Synthesis of peptides in enzymic reactions involving glutathione. Nature 166:288-292.

Hanes CS, Hird FJ, Isherwood FA. (1952). Enzymic transpeptidation reactions involving gamma-glutamyl peptides and alpha-amino-acyl peptides. Biochem J 51:25-35.

Hata K, Hayakawa M, Abiko Y, Takiguchi H. (1981). Purification and properties of gammaglutamyl transpeptidase from bovine parotid gland. Int J Biochem 13:681-692.

Heisterkamp N, Groffen J, Warburton D, Sneddon TP. (2008). The human gammaglutamyltransferase gene family. Hum Genet 123:321-332.

Heisterkamp N, Rajpertdemeyts E, Uribe L, Forman HJ, Groffen J. (1991). Identification of a human gamma-glutamyl cleaving enzyme related to, but distinct from, gamma-glutamyl transpeptidase. Proc Natl Acad Sci U S A 88:6303-6307.

Henderson GB, Hughes TR, Saxena M. (1994). Functional implications from the effects of 1chloro-2,4-dinitrobenzene and ethacrynic-acid on efflux routes for methotrexate and cholate in L1210 cells. J Biol Chem 269:13382-13389.

Hinchman CA, Matsumoto H, Simmons TW, Ballatori N. (1991). Intrahepatic conversion of a glutathione conjugate to its mercapturic acid - metabolism of 1-chloro-2,4-dinitrobenzene in isolated perfused rat and guinea-pig livers. J Biol Chem 266:22179-22185.

Hu X, Legler PM, Khavrutskii I, Scorpio A, Compton JR, Robertson KL, Friedlander AM, Wallqvist A. (2012). Probing the donor and acceptor substrate specificity of the gamma-glutamyl transpeptidase. Biochemistry 51:1199-1212.

Huseby NE. (1977). Purification and some properties of gamma-glutamyltransferase from human liver. Biochim Biophys Acta 483:46-56.

Hyde CW, Young L. (1968). Biochemical studies of toxic agents - metabolic formation of 1- and 2-menaphthylmercapturic acid. Biochem J 107:519-522.

Ikeda Y, Fujii J, Taniguchi N. (1993). Significance of Arg-107 and Glu-108 in the catalytic mechanism of human gamma-glutamyl transpeptidase - identification by site-directed mutagenesis. J Biol Chem 268:3980-3985. 
Ikeda Y, Fujii J, Taniguchi N, Meister A. (1995). Human gamma-glutamyl-transpeptidase mutants involving conserved aspartate residues and the unique cysteine residue of the light subunit. J Biol Chem 270:12471-12475.

Ikeda Y, Taniguchi N. (2005). Gene expression of gamma-glutamyltranspeptidase. Glutathione Transferases and Gamma-Glutamyl Transpeptidases 401:408-425.

Inoue M, Hiratake J, Suzuki H, Kumagai H, Sakata K. (2000). Identification of catalytic nucleophile of Escherichia coli gamma-glutamyltranspeptidase by gammamonofluorophosphono derivative of glutamic acid: N-terminal thr-391 in small subunit is the nucleophile. Biochemistry 39:7764-7771.

Josephy, P. D. \& Mannervik, B. 2006, Molecular Toxicology, $2^{\text {nd }}$ ed., 2 edn, Oxford University Press, New York.

Karkowsky AM, Bergamini MVW, Orlowski M. (1976). Kinetic studies of sheep kidney gamma-glutamyl transpeptidase. J Biol Chem 251:4736-4743.

King JB, West MB, Cook PF, Hanigan MH. (2009). A novel, species-specific class of uncompetitive inhibitors of gamma-glutamyl transpeptidase. J Biol Chem 284:9059-9065.

Lherbet C, Morin M, Castonguay R, Keillor JW. (2003). Synthesis of aza and oxaglutamyl-pnitroanilide derivatives and their kinetic studies with gamma-glutamyltranspeptidase. Bioorg Med Chem Lett 13:997-1000.

Lieberman MW, Wiseman AL, Shi ZZ, Carter BZ, Barrios R, Ou CN, ChevezBarrios P, Wang Y, Habib GM, Goodman JC, Huang SL, Lebovitz RM, Matzuk MM. (1996). Growth retardation and cysteine deficiency in gamma-glutamyl transpeptidase-deficient mice. Proc Natl Acad Sci U S A 93:7923-7926.

Liska D, Lyon M, Jones DS. (2006). Detoxification and biotransformational imbalances. Explore (NY) 2:122-140.

Lu SC. (1999). Regulation of hepatic glutathione synthesis: current concepts and controversies. FASEB J 13:1169-1183

Meister, A, Tate, SS, Griffith, OW. (1981). Gamma-Glutamyl transpeptidase. Meth Enzymol 77:237-253.

Miller SP, Awasthi YC, Srivastava SK. (1976). Studies of human kidney gamma-glutamyl transpeptidase - purification and structural, kinetic, and immunological properties. J Biol Chem 251:2271-2278.

Morin M, Rivard C, Keillor JW. (2006). Gamma-Glutamyl transpeptidase acylation with peptidic substrates: free energy relationships measured by an HPLC kinetic assay. Org Biomol Chem 4:3790-3801. 
Morrow AL, Williams K, Sand A, Boanca G, Barycki JJ. (2007). Characterization of Helicobacter pylori gamma-glutamyltranspeptidase reveals the molecular basis for substrate specificity and a critical role for the tyrosine 433-containing loop in catalysis. Biochemistry 46:13407-13414.

Northrop DB. (1998). On the meaning of $\mathrm{K}_{\mathrm{m}}$ and V/K in enzyme kinetics. J Chem Educ 75:11531157.

Okada T, Suzuki H, Wada K, Kumagai H, Fukuyama K. (2006). Crystal structures of gammaglutamyltranspeptidase from Escherichia coli, a key enzyme in glutathione metabolism, and its reaction intermediate. Proc Natl Acad Sci U S A 103:6471-6476.

Orlowski M, Meister A. (1963). Gamma-Glutamyl-p-nitroanilide - a new convenient substrate for determination and study of L- and D-gamma-glutamyltranspeptidase activities. Biochim Biophys Acta 73:6769-681.

Orning L, Hammarström S. (1982). Kinetics of the conversion of leukotriene C by gammaglutamyl transpeptidase. Biochem Biophys Res Commun 106:1304-1309.

Patterson AD, Gonzalez FJ, Idle JR. (2010). Xenobiotic metabolism: a view through the metabolometer. Chem Res Toxicol 23:851-860.

Poon JC, Josephy PD. (2012). Hydrolysis of S-aryl-cysteinylglycine conjugates catalyzed by porcine kidney cortex membrane dipeptidase. Xenobiotica, in press.

Reska M, Ochsmann E, Kraus T, Schettgen T. (2010). Accurate quantification of mercapturic acids of styrene (PHEMAs) in human urine with direct sample injection using automated column-switching high-performance liquid chromatography coupled with tandem mass spectrometry. Anal Bioanal Chem 397:3563-3574.

Sabatini L, Barbieri A, Indiveri P, Mattioli S, Violante FS. (2008). Validation of an HPLCMS/MS method for the simultaneous determination of phenylmercapturic acid, benzylmercapturic acid and $o$-methylbenzyl mercapturic acid in urine as biomarkers of exposure to benzene, toluene and xylenes. J Chromatogr B Analyt Technol Biomed Life Sci 863:115-122.

Sener A, Yardimci T. 2005. Activity determination, kinetic analyses and isoenzyme identification of gamma glutamyltransferase in human neutrophils. J Biochem Mol Biol 38:343349.

Shiotsuki T, Koiso A, Eto M. (1990). Inhibition of glutathione transferase by S-benzyl glutathione analogous to the conjugate of saligenin cyclic phosphate. Pestic Biochem Physiol $37: 121-129$.

Sies H. (1999). Glutathione and its role in cellular functions. Free Radic Biol Med 27:916-921.

Stillwell WG, Horning MG, Griffin GW, Tsang WS. (1982). Identification of new sulfurcontaining metabolites of naphthalene in mouse urine. Drug Metab Dispos 10:624-631. 
Takahashi S, Steinman HM, Ball D. (1982). Purification and characterization of gammaglutamyltransferase from rat pancreas. Biochim Biophys Acta 707:66-73.

Tarachand U. (1984). Purification and properties of gamma-glutamyl transpeptidase from rat deciduoma. J Appl Biochem 6:278-288.

Tate SS, Khadse V, Wellner D. (1988). Renal gamma-glutamyl transpeptidases: structural and immunological studies. Arch Biochem Biophys 262:397-408.

Tate SS, Meister A. (1974). Interaction of gamma-glutamyl transpeptidase with amino acids, dipeptides, and derivatives and analogs of glutathione. J Biol Chem 249:7593-7602.

Tate SS, Meister A. 1981. Gamma-Glutamyl-transpeptidase - catalytic, structural and functional aspects. Molec Cell Biochem 39:357-368.

Tsikas D, Brunner G. (1992). High-performance liquid-chromatography of glutathione conjugates .1. Ion-pair reversed-phase chromatography and UV detection. Fresenius J Anal Chem 343:326-329.

Veiga-da-Cunha M, Tyteca D, Stroobant V, Courtoy PJ, Opperdoes FR, Van Schaftingen E. (2010). Molecular identification of NAT8 as the enzyme that acetylates cysteine S-conjugates to mercapturic acids. J Biol Chem 285:18888-18898.

Vergauwen B, Dudycz LW, Dansercoer A, Devreese B. (2009). A direct spectrophotometric gamma-glutamyltransferase inhibitor screening assay targeting the hydrolysis-only mode. Biochem Biophys Res Commun 380:591-596.

Wickham S, Regan N, West MB, Kumar VP, Thai J, Li PK, Cook PF, Hanigan MH. (2012). Divergent effects of compounds on the hydrolysis and transpeptidation reactions of gammaglutamyl transpeptidase. J Enzyme Inhib Med Chem 27:476-489.

Wickham S, West MB, Cook PF, Hanigan MH. (2011). Gamma-Glutamyl compounds: substrate specificity of gamma-glutamyl transpeptidase enzymes. Anal Biochem 414:208-214.

Yang Y, Rafter J, Gustafsson JA, Sjovall J, Griffiths WJ. (1998). Analysis of the major mercapturic acid pathway metabolites of benzo[a]pyrene found in rat urine by nano-electrospray mass spectrometry. Rapid Commun Mass Spectrom 12:465-471. 


\section{APPENDICES}

\section{Appendix A: ESI-LC-MS spectra of the products of hydrolysis of GSH conjugates}

DNP-GSH, $\mathrm{m} / \mathrm{z}=474.0$

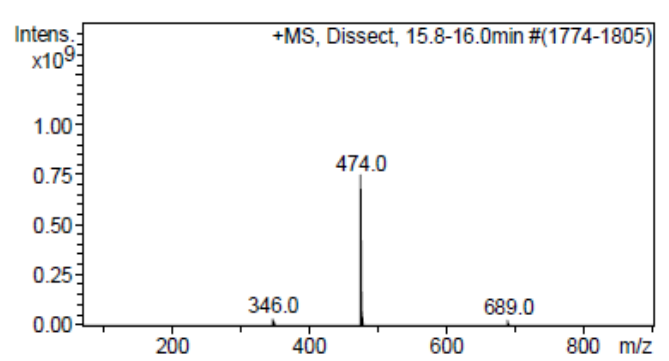

\begin{tabular}{rrr}
$\#$ & $\mathbf{m} / \mathbf{z}$ & $\mathbf{I}$ \\
\hline 1 & 346.0 & 36091496 \\
2 & 346.9 & 6562777 \\
3 & 349.0 & 22882016 \\
4 & 474.0 & 748954816 \\
5 & 475.0 & 133813656 \\
6 & 476.0 & 76717776 \\
7 & 477.0 & 8417431 \\
8 & 688.4 & 5096066 \\
9 & 689.0 & 25342266 \\
10 & 689.9 & 4885222
\end{tabular}

$\mathrm{M}-\mathrm{GSH}, \mathrm{m} / \mathrm{z}=448.1$

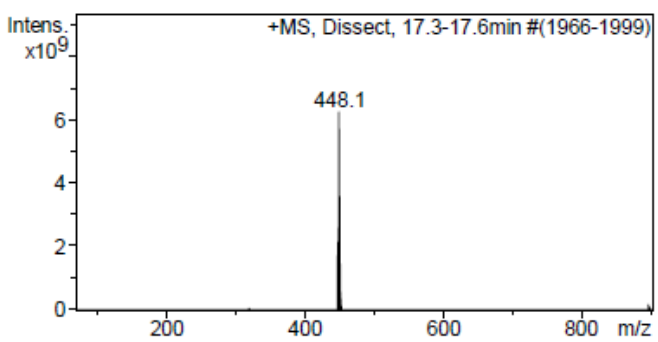

NB-GSH, m/z = 443.1

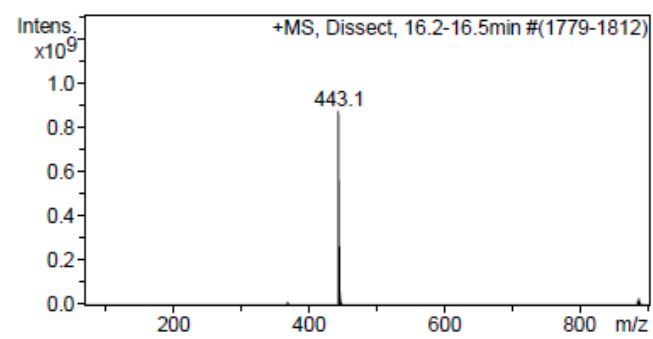

\begin{tabular}{rrr}
$\#$ & $\mathrm{~m} / \mathbf{z}$ & $\mathrm{I}$ \\
\hline 1 & 368.1 & 12466159 \\
2 & 369.0 & 9667686 \\
3 & 443.1 & 874309696 \\
4 & 444.1 & 215141552 \\
5 & 445.1 & 61501616 \\
6 & 446.1 & 18308240 \\
7 & 884.7 & 17068556 \\
8 & 885.1 & 27583582 \\
9 & 886.1 & 12754034 \\
10 & 886.9 & 8404703
\end{tabular}

MA-GSH, $\mathrm{m} / \mathrm{z}=498.1$

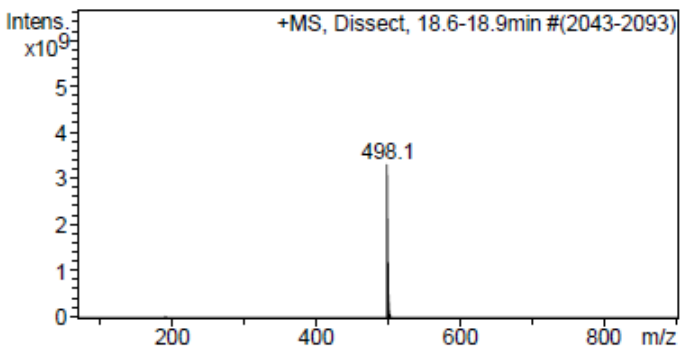

\begin{tabular}{rrr}
$\#$ & $\mathrm{~m} / \mathrm{z}$ & $\mathrm{I}$ \\
\hline 1 & 191.1 & 28278724 \\
2 & 191.9 & 10324122 \\
3 & 192.1 & 8336312 \\
4 & 498.1 & 3301275904 \\
5 & 499.1 & 983489408 \\
6 & 500.1 & 347654048 \\
7 & 500.8 & 5908134 \\
8 & 501.1 & 93472320 \\
9 & 502.1 & 26312498 \\
10 & 865.7 & 4867144
\end{tabular}


MBP-GSH, $\mathrm{m} / \mathrm{z}=474.1$

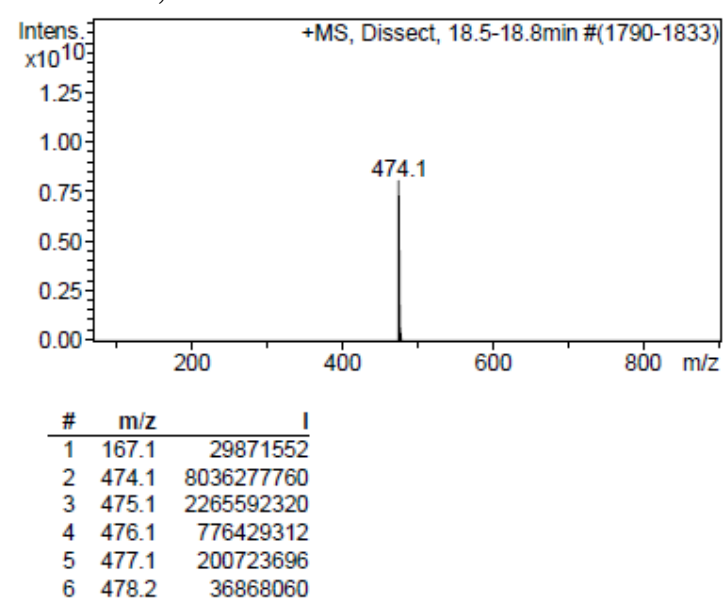




\section{Appendix B: Typical progress curves of enzyme assays with GSH conjugates}

NB-GSH; $125 \mu \mathrm{M} ; 25 \mu \mathrm{g}$ protein

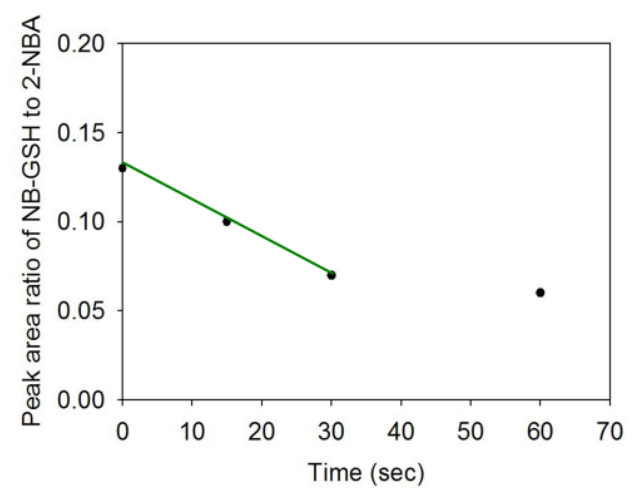

MA-GSH; $250 \mu \mathrm{M} ; 35 \mu \mathrm{g}$ protein

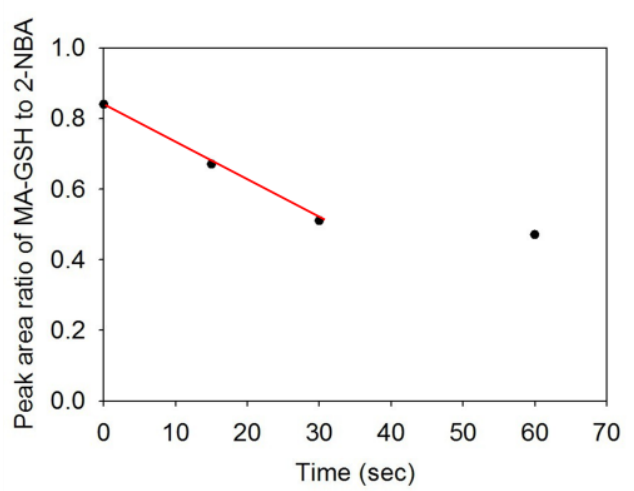

M-GSH; $100 \mu \mathrm{M} ; 45 \mu \mathrm{g}$ protein

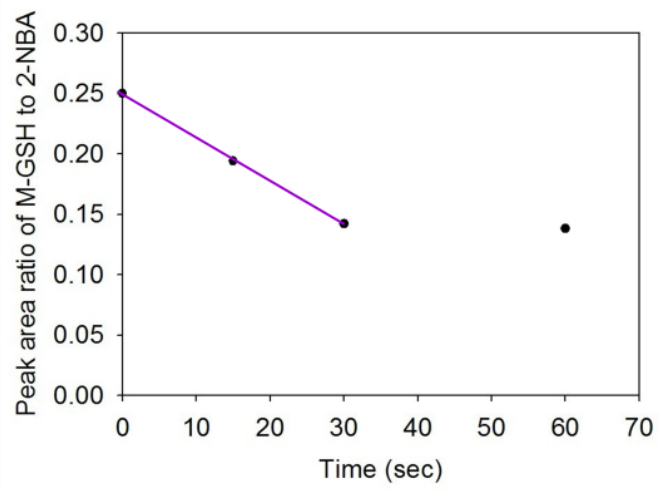

MBP-GSH; $100 \mu \mathrm{M} ; 30 \mu \mathrm{g}$ protein

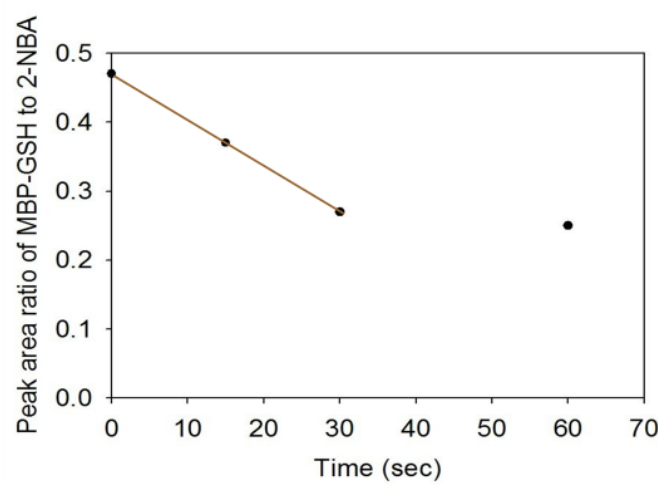




\section{Appendix C: GSH conjugate HPLC standard curves}

DNP-GSH, $\mathrm{r}^{2}=0.98$

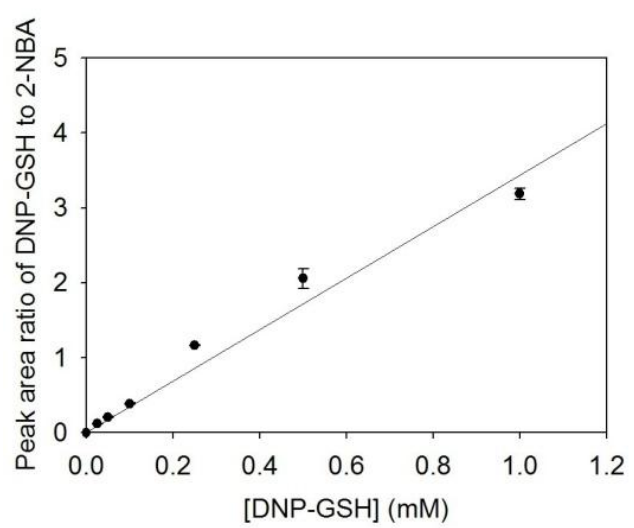

M-GSH, $\mathrm{r}^{2}=0.99$

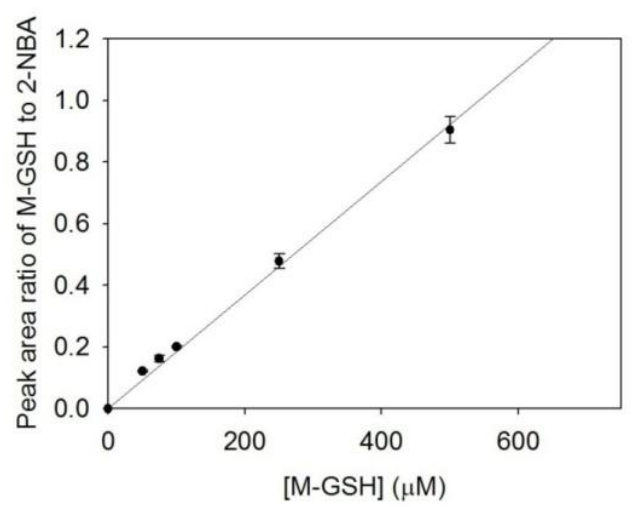

MBP-GSH, $\mathrm{r}^{2}=0.99$

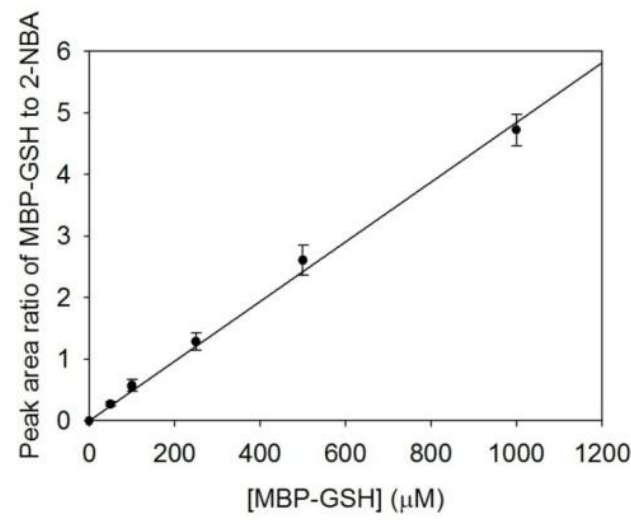

NB-GSH, $r^{2}=0.99$

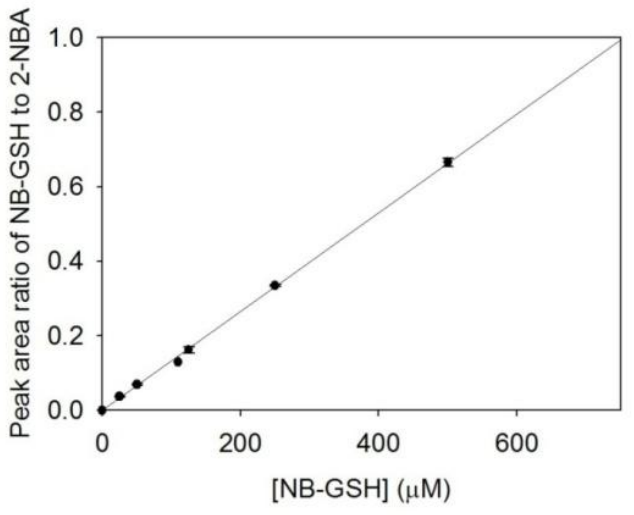

MA-GSH, $\mathrm{r}^{2}=0.99$

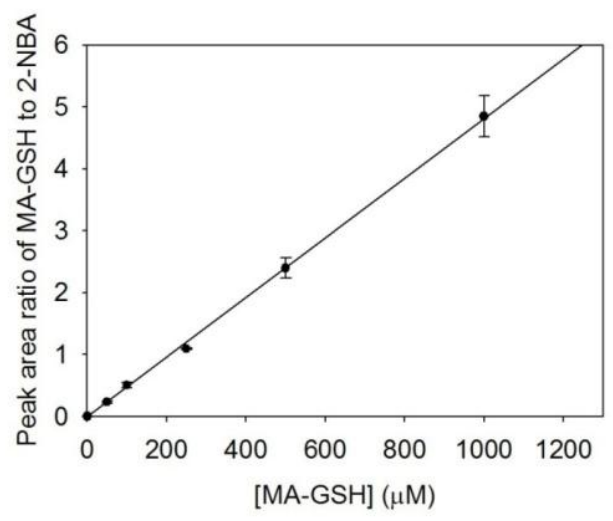


Appendix D: Chromatograms of enzymatic hydrolysis (15 sec) of GSH conjugates

DNP-GSH $(400 \mu \mathrm{M})$

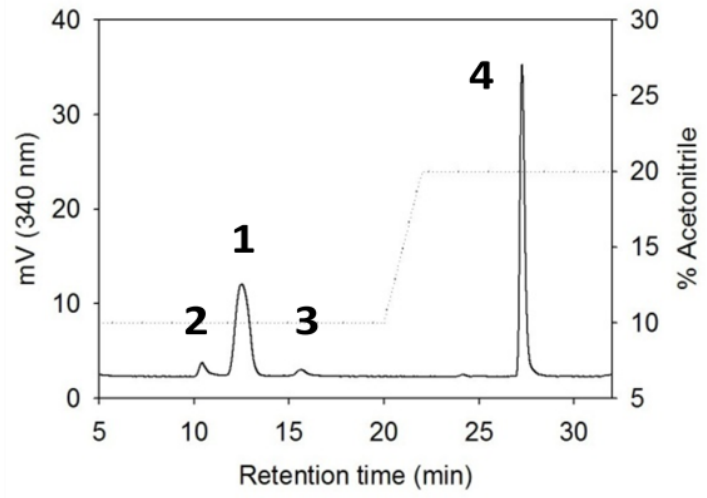

MA-GSH $(400 \mu \mathrm{M})$

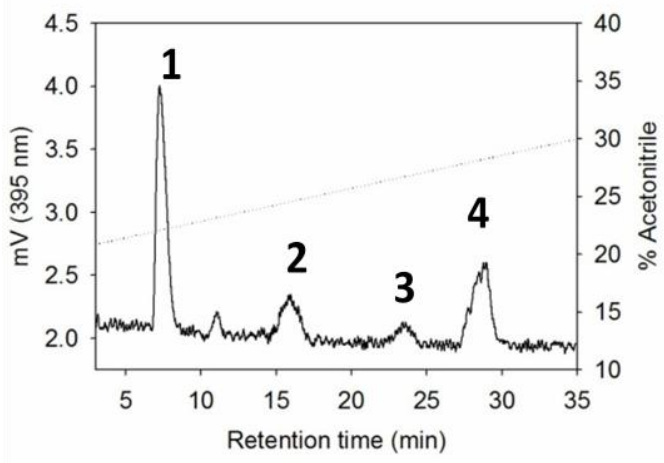

Legend

1: 2-NBA

2: Cys-Gly conjugate

3: Cys conjugate

4: GSH conjugate
NB-GSH $(250 \mu \mathrm{M})$

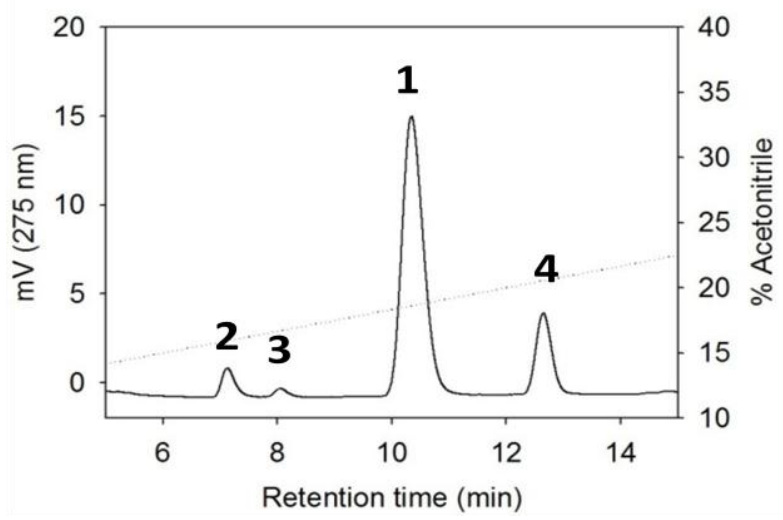

MBP-GSH $(250 \mu \mathrm{M})$

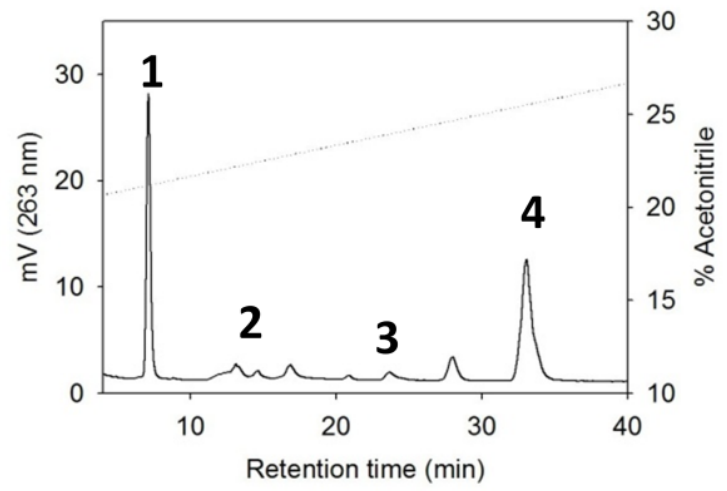

